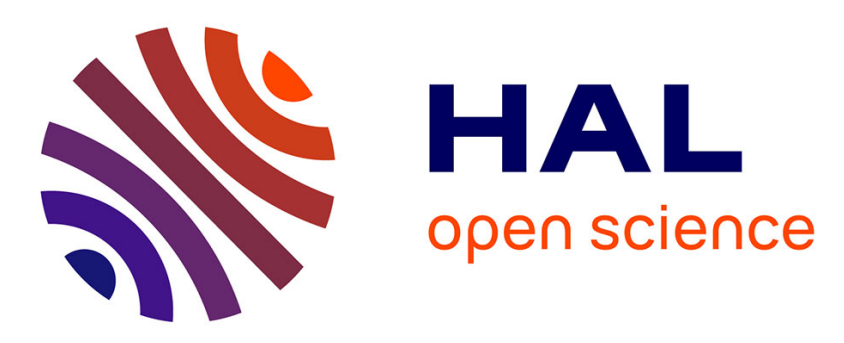

\title{
Annexin A2-dependent actin bundling promotes secretory granule docking to the plasma membrane and exocytosis.
}

Marion Gabel, Franck Delavoie, Valerie Demais, Cathy Royer, Yannick Bailly, Nicolas Vitale, Marie-France Bader, Sylvette Chasserot

\section{To cite this version:}

Marion Gabel, Franck Delavoie, Valerie Demais, Cathy Royer, Yannick Bailly, et al.. Annexin A2dependent actin bundling promotes secretory granule docking to the plasma membrane and exocytosis.. Journal of Cell Biology, 2015, 210 (5), pp.785-800. 10.1083/jcb.201412030 . hal-02655911

\section{HAL Id: hal-02655911 \\ https://hal.science/hal-02655911}

Submitted on 29 May 2020

HAL is a multi-disciplinary open access archive for the deposit and dissemination of scientific research documents, whether they are published or not. The documents may come from teaching and research institutions in France or abroad, or from public or private research centers.
L'archive ouverte pluridisciplinaire HAL, est destinée au dépôt et à la diffusion de documents scientifiques de niveau recherche, publiés ou non, émanant des établissements d'enseignement et de recherche français ou étrangers, des laboratoires publics ou privés. 


\title{
Annexin A2-dependent actin bundling promotes secretory granule docking to the plasma membrane and exocytosis
}

\author{
Marion Gabel, ${ }^{1}$ Franck Delavoie, ${ }^{3}$ Valérie Demais, ${ }^{2}$ Cathy Royer, ${ }^{2}$ Yannick Bailly, ${ }^{1}$ Nicolas Vitale, \\ Marie-France Bader, ${ }^{1}$ and Sylvette Chasserot-Golaz ${ }^{1}$

\begin{abstract}
Institut des Neurosciences Cellulaires et Intégratives, UPR3212 Centre National de la Recherche Scientifique, Université de Strasbourg, F-67084 Strasbourg, France 2Plateforme Imagerie In Vitro, Neuropôle de Strasbourg, F-67084 Strasbourg, France 3 Laboratoire de Biologie Moléculaire Eucaryote, UMR5099 Centre National de la Recherche Scientifique-Université de Toulouse III Paul Sabatier, F-3 1000 Toulouse, France
\end{abstract}

Annexin A2, a calcium-, actin-, and lipid-binding protein involved in exocytosis, mediates the formation of lipid microdomains required for the structural and spatial organization of fusion sites at the plasma membrane. To understand how annexin A2 promotes this membrane remodeling, the involvement of cortical actin filaments in lipid domain organization was investigated. 3D electron tomography showed that cortical actin bundled by annexin A2 connected docked secretory granules to the plasma membrane and contributed to the formation of GM1-enriched lipid microdomains at the exocytotic sites in chromaffin cells. When an annexin A2 mutant with impaired actin filament-bundling activity was expressed, the formation of plasma membrane lipid microdomains and the number of exocytotic events were decreased and the fusion kinetics were slower, whereas the pharmacological activation of the intrinsic actin-bundling activity of endogenous annexin A2 had the opposite effects. Thus, annexin A2-induced actin bundling is apparently essential for generating active exocytotic sites.

\section{Introduction}

Exocytosis of vesicular contents through the fusion of secretory vesicles/granules with the plasma membrane is a fundamental cellular process involved in many cellular functions, including cell migration, wound repair, neurotransmission, and hormone secretion. In neurons and neuroendocrine cells, calcium-dependent exocytosis has been a topic of intense investigation for decades, and many molecular players that orchestrate secretory vesicle recruitment, docking, and fusion with the plasma membrane have been identified (Jahn and Fasshauer, 2012). However, the functional characteristics of the exocytotic sites that ensure vesicle tethering to appropriate active membrane areas and assembly of the exocytotic machinery (Ammar et al., 2013) remain poorly understood. Distinct lipid compositions within the plasma membrane have been proposed to provide spatial cues to recruit and assemble components of the exocytotic machinery. For instance, cholesterol-enriched lipid microdomains (rafts) formed at granule docking sites could play this role based on the finding that proteins required for exocytosis are associated with cholesterol-dependent regions in the plasma membrane (Chasserot-Golaz et al., 2010; Sebastião et al., 2013). In addition, phosphatidylinositol 4, 5-bisphosphate $\left(\mathrm{PI}(4,5) \mathrm{P}_{2}\right)$ has been shown to form microdomains in the plasma membrane,

Correspondence to Sylvette Chasserot-Golaz: chasseroł@inci-cnrs.unistra.fr Abbreviations used in this paper: AnxA2, Annexin A2; DBH, dopamine- $\beta$-hydroxylase; $\mathrm{PI}(4,5) \mathrm{P}_{2}$, phosphatidylinositol 4, 5-bisphosphate; PSF, prespike foot; TEM, transmission electron microscopy; WA, withaferin A; WT, wild type. which seems to be required for efficient SNARE-mediated granule docking and fusion with the plasma membrane (Aoyagi et al., 2005; Lang, 2007). In chromaffin cells, we have previously found that secretagogue-evoked stimulation induces the de novo formation of ganglioside GM1/cholesterol/PI(4,5)P2-enriched lipid microdomains, which seem necessary for catecholamine secretion (Chasserot-Golaz et al., 2005; Umbrecht-Jenck et al., 2010). All together, these data suggest that the occurrence of an unknown regulated mechanism responsible for lipid segregation and clustering creates exocytotic sites.

Annexin A2 (AnxA2) belongs to a family of calcium-, actin- and phospholipid-binding proteins that are widely expressed in eukaryotic cells. Annexins have emerged as important links between intracellular $\mathrm{Ca}^{2+}$ signals and the regulation of various membrane functions such as regulating the organization of membrane domains and/or linking the cytoskeleton to the plasma membrane (Gerke et al., 2005). AnxA2 can exist as a monomer or as part of a heterotetrameric complex with the protein S100A10, where the central S100A10 dimer binds two AnxA2 chains, forming a scaffold that can bridge opposing membrane surfaces and actin filaments (Lewit-Bentley et al., 2000). There is growing evidence that AnxA2 is involved in

(C) 2015 Gabel et al. This article is distributed under the terms of an AttributionNoncommercial-Share Alike-No Mirror Sites license for the first six months after the publication date (see http://www.rupress.org/terms). After six months it is available under a Creative Commons License (Attribution-Noncommercial-Share Alike 3.0 Unported license, as described at http://creativecommons.org/licenses/by-nc-sa/3.0/). 
calcium-dependent exocytosis (Bharadwaj et al., 2013). Using a gene knockdown strategy in chromaffin cells, we have previously described a role for AnxA2 in the formation of the GM1/ cholesterol/PI(4,5) $\mathrm{P}_{2}$-enriched lipid microdomains at granule docking sites after cell stimulation (Chasserot-Golaz et al., 2005; Umbrecht-Jenck et al., 2010). Hence, AnxA2 exhibits many attractive properties to ensure lipid domain coalescence. It binds lipids in a $\mathrm{Ca}^{2+}$-dependent manner (Gokhale et al., 2005) and displays an F-actin-bundling activity when interacting with S100A10 (Donato, 2001). As the actin cytoskeleton has also been proposed to act as a scaffold that forms organized lipid domains and recruits selected proteins (Sankaranarayanan et al., 2003; Dinic et al., 2013), we investigated whether AnxA2 could organize actin filaments to promote the formation of lipid microdomains in the plasma membrane. These results reveal that AnxA2 and the actin cytoskeleton are essential partners to provide lipid platforms for granule recruitment and fusion, and challenge the classical role depicted for the cortical actin cytoskeleton in calcium-dependent exocytosis.

\section{Results}

Actin filaments contribute to the formation of GM1-enriched granule docking sites in nicotine-stimulated chromaffin cells

We first investigated whether actin filaments were associated with the lipid domains formed at the exocytotic sites in nicotine-stimulated cells. A triple labeling experiment was performed using phalloidin to detect F-actin, anti-dopamine- $\beta$-hydroxylase $(\mathrm{DBH})$ antibodies to visualize exocytotic sites (Chasserot-Golaz et al., 2005), and fluorescent cholera toxin to label GM1-enriched domains (Harder et al., 1998; Janes et al., 1999). In unstimulated chromaffin cells (Fig. 1 A), actin formed a cortical network, which is classically believed to prevent chromaffin granule docking at the plasma membrane (Sontag et al., 1988). No DBH patches were detected, confirming the low basal secretory activity in the absence of a secretagogue, and only a weak staining with cholera toxin was observed at the cell surface. In nicotine-stimulated cells, the actin barrier was partially removed, a patchy DBH staining pattern appeared at the cell surface, and the binding of fluorescent cholera toxin was concomitantly increased, revealing the formation of GM1-enriched microdomains. Residual F-actin colocalized with both GM1-enriched domains and DBH-positive exocytotic sites as shown in mask images (Fig. 1 A). Quantification of the relative proportion of F-actin associated with cholera toxin or $\mathrm{DBH}$ indicated that, in stimulated chromaffin cells, $\sim 50 \%$ of the residual actin filaments were associated with GM1 domains and exocytotic sites (Fig. 1 B).

Using immunogold electron microscopy, the distribution of actin and GM1 was studied on native plasma membrane sheets prepared from unstimulated or nicotine-stimulated chromaffin cells (Wilson et al., 2004; Umbrecht-Jenck et al., 2010). In unstimulated cells, GM1 (6 nm gold particles) was uniformly dispersed in small clusters containing 2-3 particles (circles in Fig. $1 \mathrm{C}$ and Fig. S1). Actin formed dark filamentous structures as revealed using anti-actin antibodies (10 nm gold particles), some of them connecting granules docked to the plasma membrane (Fig. $1 \mathrm{C}$ ). Conversely, in nicotine-stimulated cells, GM1 was found in larger clusters associated with actin filaments near docked granules (Fig. 1 C). An increase in the amount of actin was also observed at the surface of docked granules, suggesting that secretory granules were coated with actin during exocytosis. Numerical analysis of the particle distribution relative to the granules showed that actin and GM1 were concentrated in a 0.1$\mu \mathrm{m}$ zone from the edge of granules (Fig. 1 D). Analysis of the spatial distribution of GM1 and actin using Ripley's K function confirmed that GM1 was randomly distributed in unstimulated cells. However, in nicotine-stimulated cells (Fig. 1 F), GM1 significantly clustered with actin in domains with a radius of 180 $200 \mathrm{~nm}$ (Fig. $1 \mathrm{E}$ ). Thus, the increase of cholera toxin binding observed at the surface of stimulated cells by light microscopy (Fig. $1 \mathrm{~A}$ ) is likely to be the result of the coalescence of GM1 nanodomains triggered by cell stimulation (Chasserot-Golaz et al., 2005). Collectively, these results suggest that in chromaffin cells, secretagogues induce the formation of GM1-enriched microdomains associated with actin filaments and docked secretory granules at the plasma membrane.

To assess the role of these actin filaments in the formation of GM1-enriched domains, chromaffin cells were treated with $50 \mu \mathrm{M}$ latrunculin B to depolymerize F-actin (Gasman et al., 2004). Latrunculin B caused the disappearance of the actin filaments associated with docked granules on plasma membrane sheets from nicotine-stimulated cells (Fig. 1 C, Latrunculin B). Secretory granules also appeared smoother, possibly because of the absence of their actin coating. In parallel, latrunculin B impaired GM1 labeling, which was randomly distributed as in unstimulated membranes (Fig. 1 F). Thus, latrunculin B inhibited the formation of GM1 clusters in nicotine-stimulated chromaffin cells, suggesting that F-actin is involved in the formation of GM1-enriched domains during exocytosis.

Electron tomography was then used to determine architectural details of the spatial organization of the actin filaments present at the inner face of the plasma membrane in nicotine-stimulated cells (Fig. 2 and Video 1). As seen on a 3D representation of docked granules obtained from tomographic slices (Fig. 2, C-H), actin filaments labeled with anti-actin antibodies formed a meshwork running parallel to the plasma membrane (Fig. 2 B, in blue) and connected secretory granules to the plasma membrane (Fig. 2 B, in green). Equatorial sections of docked granules (Fig. 2 I) revealed anchoring points for actin filaments on the granule surface. Moreover, the granule surface was covered with actin filaments (Fig. $2 \mathrm{~J}$ ), confirming the presence of an actin coating on granules docked at exocytotic sites.

The side-view of tilt transmission electron microscopy (TEM) series reconstructions of docked granules at different stages of fusion clearly showed that actin bundles linked secretory granules to the plasma membrane (PM) through specific membrane-associated structures (Fig. 3 A, V). These structures could correspond to the fine strands cross-linking granules to the plasma membrane previously revealed by quick-freeze, deepetch electron microscopy (Nakata et al., 1990). These actin filaments were also observed when granules collapsed gradually to fuse with the plasma membrane. As recently described by Chiang et al. (2014), the size of the granules undergoing exocytosis seemed to decrease. It is interesting to note the positive curvature of the plasma membrane under docked granules that could be caused by forces exerted by the formation of actin bundles. Fig. 3 B shows that actin filaments connected secretory granules to the plasma membrane at anchor points localized in an area of 90-250 $\mathrm{nm}$ around the granule. This area corresponds to the $0.1-\mu \mathrm{m}$ zone from the edge of granules where GM1 and AnxA2 beads were concentrated (Fig. 1 D; also see Fig. 4 B) 
A GM1

$\mathbf{U}$
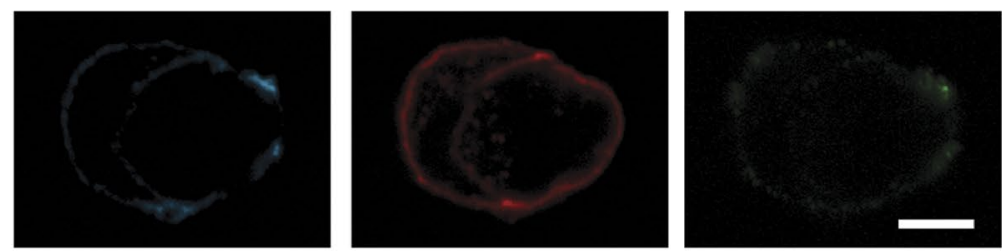

$\mathbf{S}$
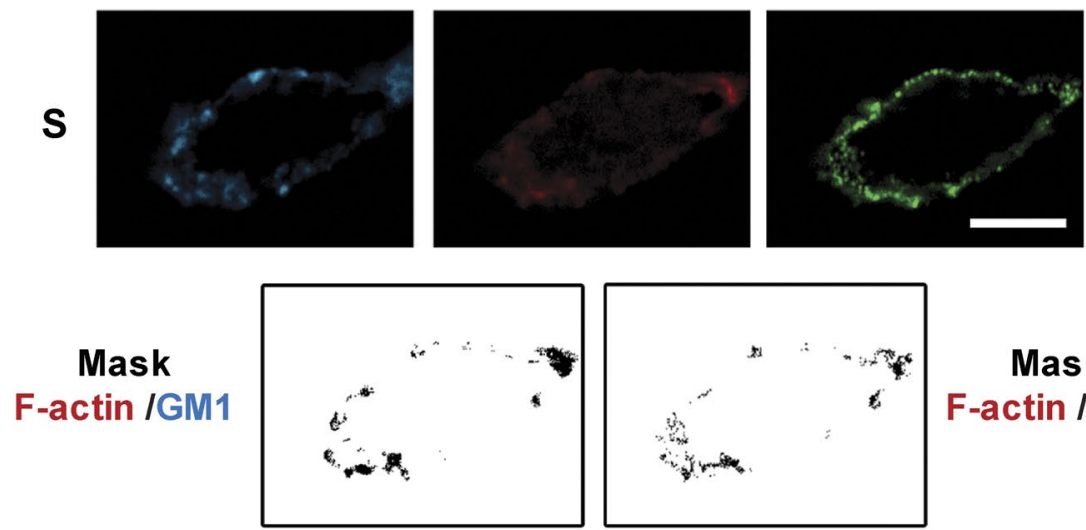

C
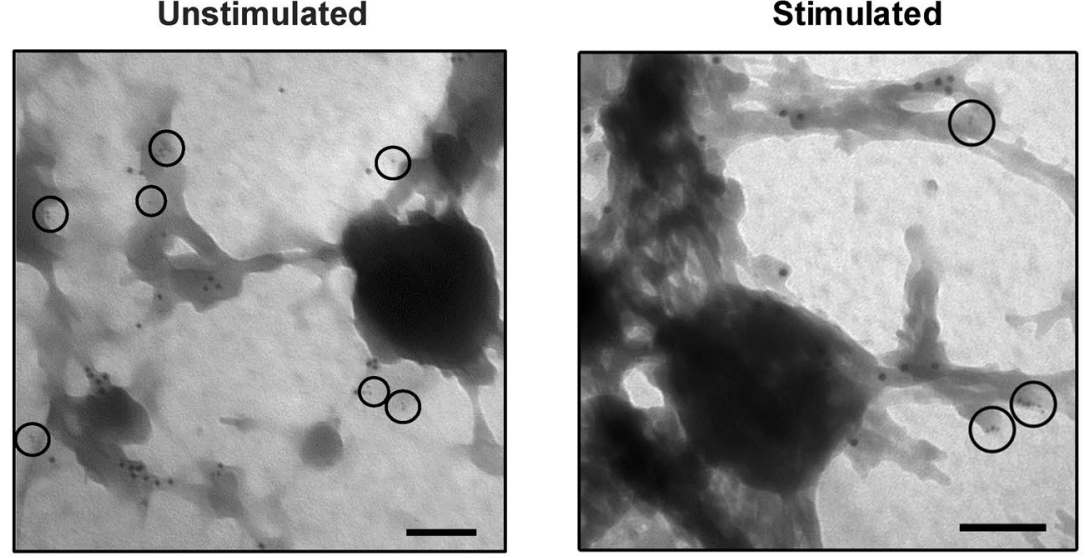

Stimulated

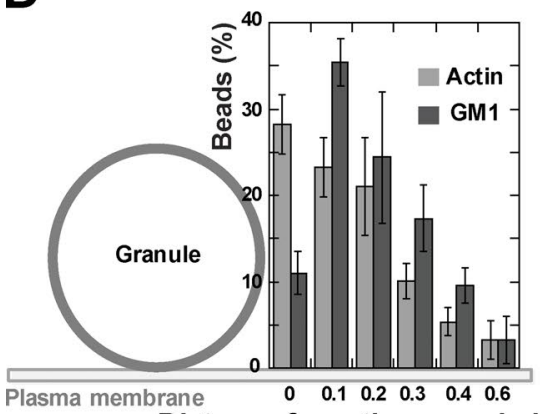

Distance from the granule border

$(\mu \mathrm{m})$
E
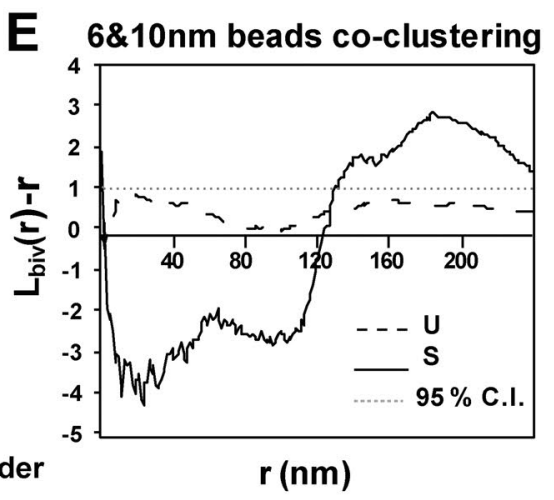

B

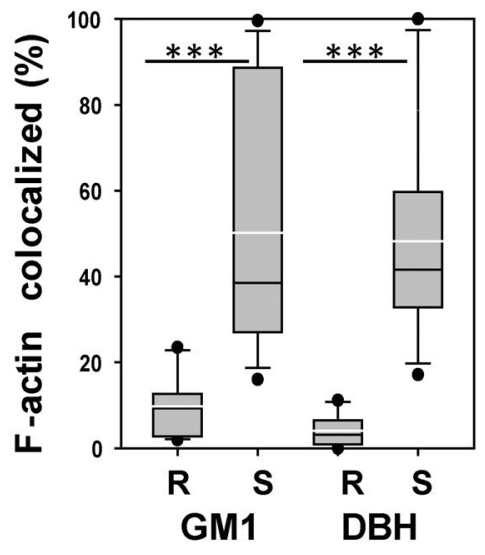

Figure 1. F-actin and GMI colocalize in microdomains formed at exocytotic sites. (A) Chromaffin cells were unstimulated (U) or stimulated for 10 min with nicotine (S) in the presence of anti-DBH antibodies and Alexa Fluor 633-conjugated cholera toxin. Cells were then fixed and labeled with TRITC-phalloidin and Alexa Fluor 488-conjugated anti-rabbit antibodies to reveal DBH staining. Merged images were recorded in the same optical section. Bars, 10 pm. Masks representing the colocalization area (phalloidin/cholera toxin or phalloidin/DBH) were generated by selecting the double-labeled pixels. (B) Semiquantitative analysis of the percentage of F-actin colocalized with GM1 and exocytotic sites. Asterisks indicate statistical significance (***, P $<0.001$ ) for medians (black line) determined using a Mann-Whitney test and the white line represents the mean $( \pm S E M ; n=20)$. Similar results were obtained on two culture preparations. (C) Distribution of GMI and actin on plasma membrane sheets visualized by immunogold labeling and electron microscopy. Membrane sheets were prepared from untreated cells or cells stimulated with $20 \mu \mathrm{M}$ nicotine in the presence of biotinylated cholera toxin to detect external GM1. Cells were treated with $50 \mu \mathrm{M}$ latrunculin B where indicated. Membranes were then incubated with anti-actin antibodies revealed with anti-rabbit antibodies coupled to $10 \mathrm{~nm}$ gold particles and streptavidin coupled to $6 \mathrm{~nm}$ gold particles to reveal cholera toxin/GM1. Bars, $100 \mathrm{~nm}$. (D) Histogram 
and may constitute the dynamic platform in which protein and lipid diffusion is restricted (Saka et al., 2014).

AnxA2 is present at GM1-enriched granule docking sites in nicotine-stimulated cells As AnxA2 is known to translocate to the cell periphery upon stimulation (Chasserot-Golaz et al., 2005; Umbrecht-Jenck et al., 2010), the distribution of AnxA2 and actin filaments on plasma membrane sheets obtained from unstimulated (Fig. 4 A) and nicotine-stimulated chromaffin cells were compared (Fig. 4 B). Double immunogold staining with anti-AnxA2 antibodies and phalloidin revealed that in unstimulated conditions, low AnxA2 and actin labelings were observed (Fig. 4 A), whereas in stimulated cells, AnxA2 colocalized with F-actin in clusters found at the anchoring base of docked granules (Fig. 4 B). Ripley's $\mathrm{K}$-function statistical analysis indicated that AnxA2 and F-actin colocalized in domains whose radius was on the order of 80-120 nm (Fig. 4 C). This close association between AnxA2 and $\mathrm{F}$-actin is consistent with the actin-binding properties of AnxA2 (Hayes et al., 2006).

In plasma membranes prepared from nicotine-stimulated cells, GM1/actin gold particles could also be observed in dark structures devoid of docked granules (Fig. 4 D). Since these structures were not seen in unstimulated cells, they could correspond to either docking sites from which granules had detached during the membrane sheet preparation or "pre-exocytotic sites" before granule recruitment. A triple immunolabeling of membrane sheets prepared from nicotine-stimulated chromaffin cells was performed using a combination of 6,10 , and $15 \mathrm{~nm}$ gold particles to covisualize GM1, S100A10, and AnxA2 (Fig. 4 E), or GM1, actin, and syntaxin-1 (Fig. 4 F). GM1-enriched microdomains formed in nicotine-stimulated cells also contained the AnxA2 tetramer (S100A10 and AnxA2), actin filaments, and the SNARE protein synataxin1. Considering that AnxA2 is recruited close to syntaxin1 and Vamp2 (Umbrecht-Jenck et al., 2010), these AnxA2/GM1/actin domains could represent functional lipid domains corresponding to genuine "pre-exocytotic sites," where secretory granules subsequently dock and fuse.

\section{AnxA2 bundles actin filaments to form GM1-enriched domains at exocytotic sites} Upon its calcium-dependent binding to F-actin, AnxA2 undergoes a conformational change that induces self-association and bundling of actin filaments (Bharadwaj et al., 2013). To investigate whether AnxA2 modifies cortical actin dynamic and thereby mediates the formation of GM1 membrane domains in nicotine-stimulated cells, an AnxA2 mutant with impaired F-actin bundling activity was created (Jones et al., 1992). The actin binding and aggregating activities of AnxA2 wild type (AnxA2-WT) and AnxA2-K286A were first compared in vitro using GST-coupled recombinant proteins incubated with F-actin in the absence or presence of calcium. Calcium similarly increased the amount of F-actin pulled down by GST-AnxA2-WT and GST-AnxA2-K86A (Fig. 5 A), indicating that both proteins were able to bind and aggregate F-actin in a calcium-dependent manner. However, the ultrastructure of F-actin/AnxA2 aggregates was quite different (Fig. 5 B). Large, linear actin filament bundles were observed with AnxA2-WT (Fig. 5 B, inset), whereas disorganized aggregates were observed with AnxA2-K286A, thus confirming that the mutant has lost its actin bundling activity.

Thereafter, AnxA2-WT and AnxA2-K286A were expressed in chromaffin cells as C-terminal GFP fusion proteins to maintain their biochemical and functional properties (Zobiack et al., 2001; Rescher et al., 2008), and cells were stimulated with nicotine, in the presence of cholera toxin to visualize GM1 domain formation, and then stained with TRITC-phalloidin. As shown in Fig. $5 \mathrm{C}$, stimulation induced the translocation of WT and mutant AnxA2 proteins to the cell periphery, but compared with cells expressing the WT protein, very little cell surface binding of cholera toxin was observed in cells expressing AnxA2-K286A-GFP (Fig. 5 C). A semiquantitative analysis confirmed that AnxA2-K286A-GFP expression reduced both cholera toxin and $\mathrm{F}$-actin labelings at the cell periphery (Fig. 5 D). Thus, the actin-bundling activity of AnxA2 seems essential to form and/or stabilize the GM1-enriched microdomains forming exocytotic sites in nicotine-stimulated cells.

Withaferin A (WA), a natural compound derived from plants, increases AnxA2 affinity for actin filaments and its F-actin-bundling activity (Falsey et al., 2006; Ozorowski et al., 2012). To support the assumption that AnxA2 mediates the formation of GM1 membrane domains by modifying cortical actin dynamics, the effects of WA on actin filaments and the formation of GM1 clusters were studied in nicotine-stimulated chromaffin cells. As shown in Fig. 6 (A and B), WA treatment increased the peripheral labeling of cholera toxin and phalloidin in nicotine-stimulated cells, suggesting that the actin-bundling activity of AnxA2 is linked to the formation of GM1-enriched microdomains at the plasma membrane. Indeed, electron tomography of plasma membrane sheets prepared from WA-treated cells confirmed the increase in cortical actin meshwork (Fig. 6 C). 3D tomographic representations of docked granules (Fig. $6 \mathrm{D}$ and Video 2), side-views of tilt TEM series reconstructions of a docked granule (Fig. $6 \mathrm{E}$ ), and plot profiles (Fig. 6, F-I) all clearly revealed an increase in thickness of the actin coat and bundles connecting secretory granules to the plasma membrane. All together, these results suggest that AnxA2 mediates the formation of GM1 microdomains through its actin-bundling activity, thereby forming exocytotic sites in nicotine-stimulated cells.

\section{AnxA2 F-actin-bundling activity is involved in secretory granule recruitment and fusion} during exocytosis

The involvement of AnxA2 F-actin-bundling activity in catecholamine release was investigated using carbon fiber amperometry to determine the frequency and kinetics of individual exocytotic events (Poëa-Guyon et al., 2013; Table 1). Fig. 7 A

representing the relative distribution of $6 \mathrm{~nm}$ and $10 \mathrm{~nm}$ gold particles according to their distance from a granule $(\mathrm{error}$ bars indicate \pm SEM; $n=40$ images). The distance and number of particles were determined manually. Note that GM1-bound particles and actin-bound particles are concentrated within $0.1 \mathrm{\mu m}$ from the granule edge. A significant number of actin-bound particles were located on the granules (<25 nm away). (E) Bivariate K-function analysis of double-labeled membranes. Images obtained in unstimulated (15) and nicotine-stimulated (20) cells were analyzed. Values of L(r)-r greater than the $95 \% \mathrm{Cl}$ indicated the significant coclustering of actin and GM1. (F) Spatial point pattern analysis of GM1 labeling. For each condition, 30 images were analyzed and experiments were performed on two different cell cultures. Values of L(r)-r greater than the $95 \% \mathrm{Cl}$ indicated significant $\mathrm{GM} 1 \mathrm{clustering}$ in nicotine-stimulated cells, whereas a random pattern was seen in untreated cells and nicotine-stimulated cells treated with latrunculin $B$. 

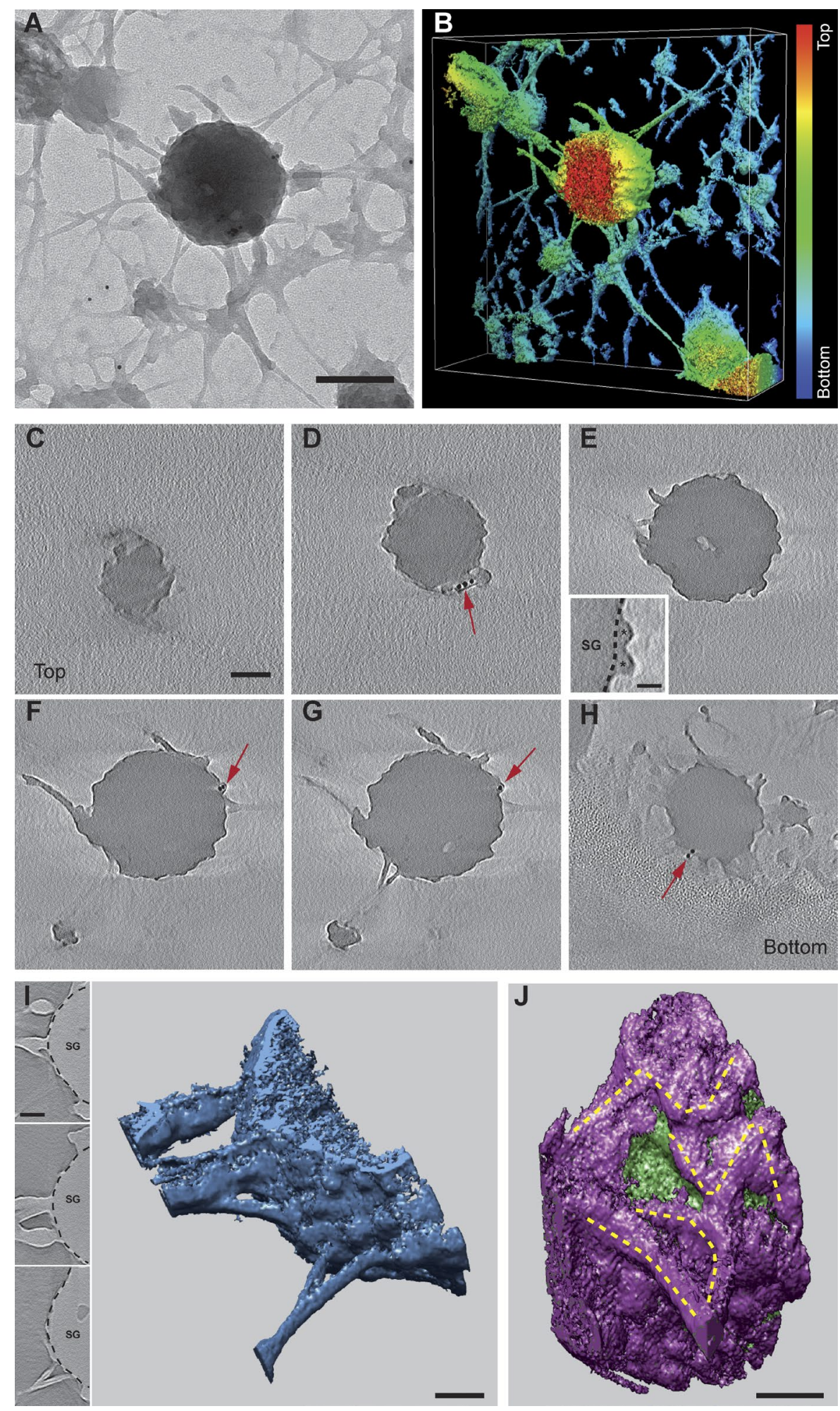

Figure 2. Electron tomography of the cortical actin network surrounding secretory granules docked at the plasma membrane. (A) Electron micrograph showing a plasma membrane prepared from a nicotine-stimulated cell. Secretory granules docked at the plasma membrane were surrounded by a filamentous network. (B) A 3D model of the granule in A showing the close interaction between docked secretory granules and the cortical F-actin network covering the inner face of the plasma membrane. False colors were applied using a color code related to the topographic height (shown on the right), with the plasma membrane sheets as the lowest plane (Video 1). (C-H) Series of tomographic slices of the docked granule in A. The first (Top) and last sections (Bottom) correspond, respectively, to the farthest and closest parts of the docking region of secretory granules at the plasma membrane. Actin colloidal gold immunostaining (arrows) served as a fiducial marker for image alignment during tomographic reconstruction. The inset in $\mathrm{E}$ is a $2.5 \times$ enlargement of the granule whose limit is shown as a broken black line. The asterisks indicate the protrusions that correspond to anchored F-actin. SG, secretory granule. (I) Surface-rendered view of a subtomogram corresponding to an equatorial section of the granule shown in A. The 3D representation is associated with the three tomographic sections (left) showing different branched anchoring structures that are connected to the granule. (J) Surface-rendered view of a subtomogram corresponding to a longitudinal section of the granule shown in A. The volume eraser tool in UCSF Chimera was used to perform curettage inside the granule until reaching the membrane. The topography of the granule surface is displayed in purple. The excess removed by curettage is shown in green. The path followed by the actin filaments is represented by the broken yellow lines. Bars: (A) $200 \mathrm{~nm}$; (C) 100 $\mathrm{nm}$; (E, inset) $25 \mathrm{~nm}$; (I and J) $25 \mathrm{~nm}$. shows representative amperometric traces recorded from chromaffin cells expressing AnxA2-K286A or treated with WA. AnxA2-K286A decreased the frequency of the amperometric events by $60 \%$, whereas WA increased it (Fig. 7 B), suggesting that the actin filament-bundling activity of AnxA2 partly controls the number of secretory granules undergoing exocytosis.

Thereafter, the shape of individual amperometric spikes was analyzed. Each spike represents a single granule fusion event with a surface area or quantal size that is proportional to the amount of catecholamine released per event, with the spike height (amplitude) reflecting the maximal flux of catecholamine, the half-width reflecting the duration of the exocytotic event, and the rise time reflecting the kinetics of the fusion pore expansion (Fig. 7 C). Both AnxA2-K286A and WA affected some of these spike parameters (Fig. 7 D). Although the quantal size of the spikes was not affected, the half-width, the mean spike amplitude, and the spike rise time were modified in cells expressing AnxA2-K286A or treated with WA. Note that WA, 
A

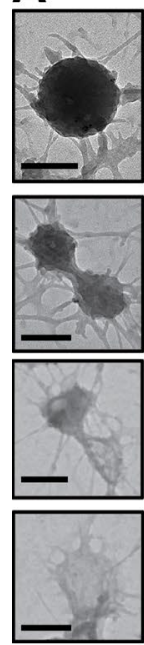

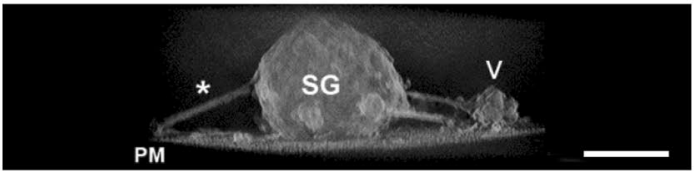
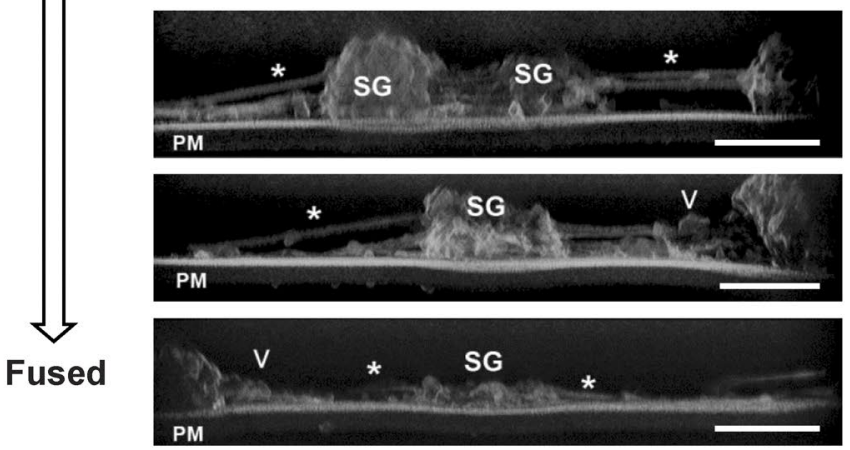

B
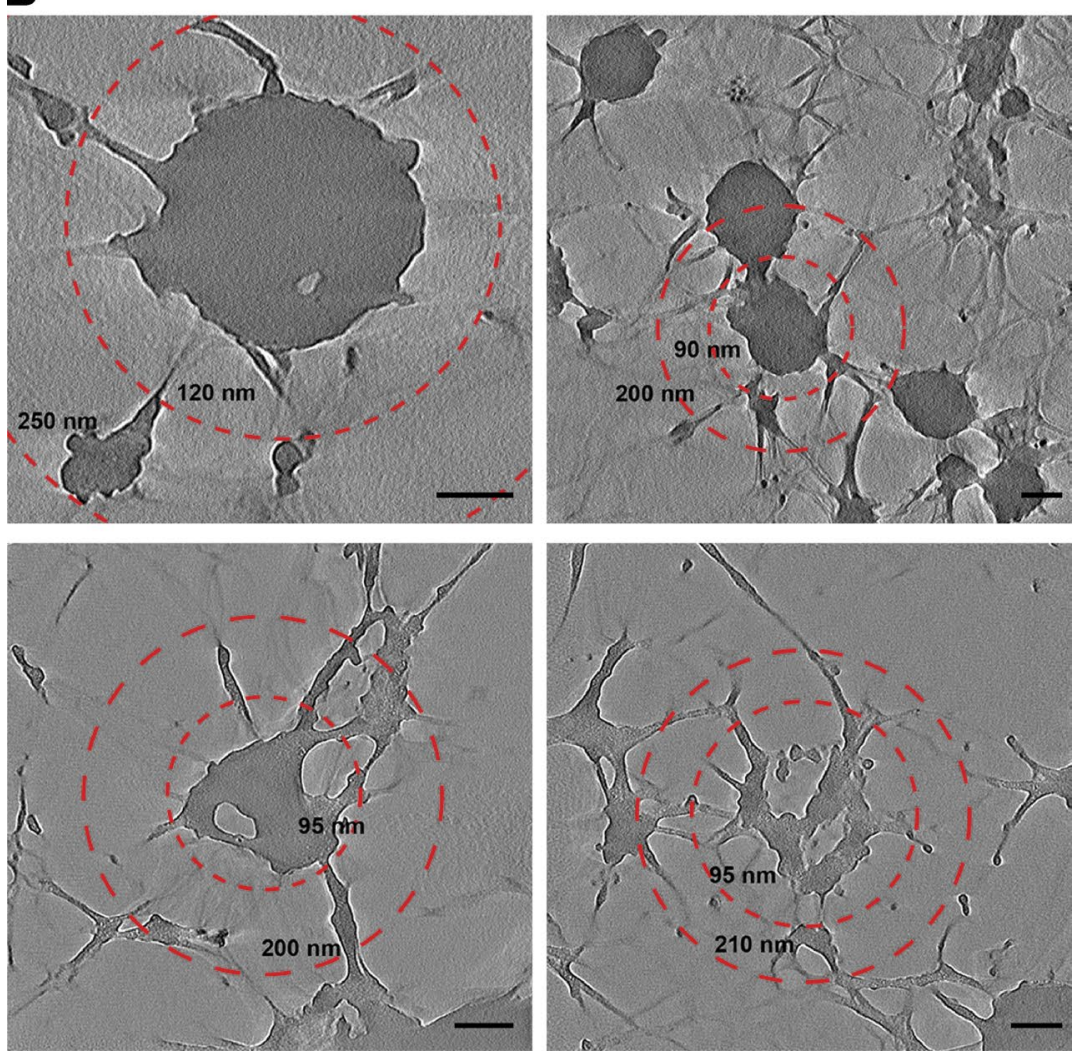

which potentially increases the F-actin-bundling activity of endogenous AnxA2, and AnxA2-K286A devoid of F-actin-bundling activity had opposite effects on these spike parameters.

Amperometric spikes are often preceded by the so-called prespike foot (PSF) currents, believed to reflect the slow release of catecholamines through an initial narrow fusion pore, before its subsequent rapid expansion that gives rise to the spike. Significant changes in PSF parameters were also observed (Fig. 8 and Table 1). Chromaffin cells expressing AnxA2-K286A exhibited significantly longer PSF $(24.3 \pm 2.1 \mathrm{~ms}$ versus $15.7 \pm$ $2.1 \mathrm{~ms}$ in nontransfected cells) and an increase in foot charge $(+30 \%)$, whereas WA-treated cells showed shorter and smaller PSF. Thus, these amperometric data are consistent with a role for AnxA2-dependent actin filament-bundling activity in
Figure 3. Spatial organization of actin filaments connecting secretory granules to the plasma membrane. (A) TEM images at zero tilt of a docked secretory granule and a series of secretory granules at different stages of fusion (left) and the corresponding clipping plane of the side view of the isosurface representation of their tomogram (right). Actin cytoskeleton favoring exocytosis (asterisks) of secretory granules (SG) is clearly linked to the plasma membrane (PM) through specific associated-membrane structures (V). Bars, $200 \mathrm{~nm}$. (B) Slices through a tomogram of docked and fusing secretory granules. Red broken circles define an area of 90 $250 \mathrm{~nm}$ around the granules, wherein anchor points for cortical actin at the plasma membrane were systematically localized. Bars, $100 \mathrm{~nm}$. the recruitment of secretory granules (number of exocytotic events), and possibly in the stabilization of the nascent fusion pore and its enlargement, thereby allowing full fusion in the late stage of exocytosis.

Finally, to address the causal relationship between AnxA2-induced actin bundling and granule recruitment and docking, we counted the number of docked granules on membrane sheets prepared from stimulated chromaffin cells expressing either AnxA2-WT or AnxA2-K286A. Immunogold labeling of GFP ( $25 \mathrm{~nm}$ gold particles) was used to identify membrane sheets of transfected cells. As illustrated in Fig. 9, the number of docked granules was higher in stimulated than in resting cells ( 0.08 and 0.022 granules $/ \mu \mathrm{m}^{2}$, respectively) in cells that were not transfected or in cells expressing AnxA2-WT. However, the 
A

F-actin (6) \& AnxA2 (10)

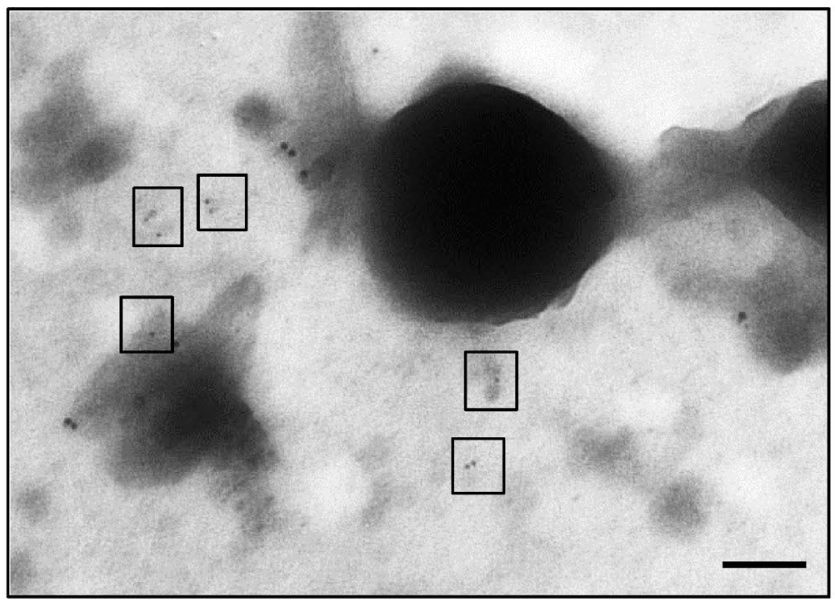

B

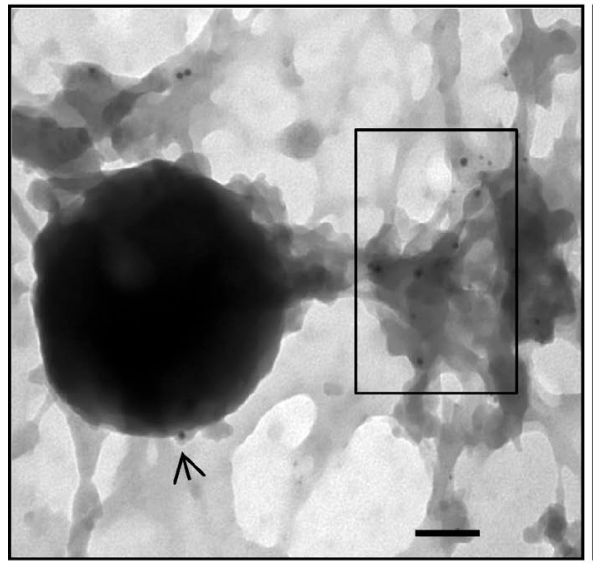

F-actin (6) \& AnxA2 (10)

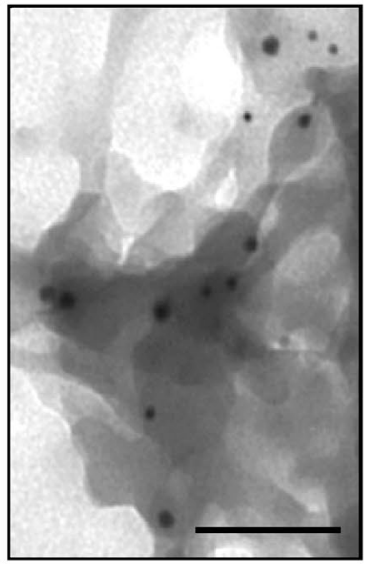

C

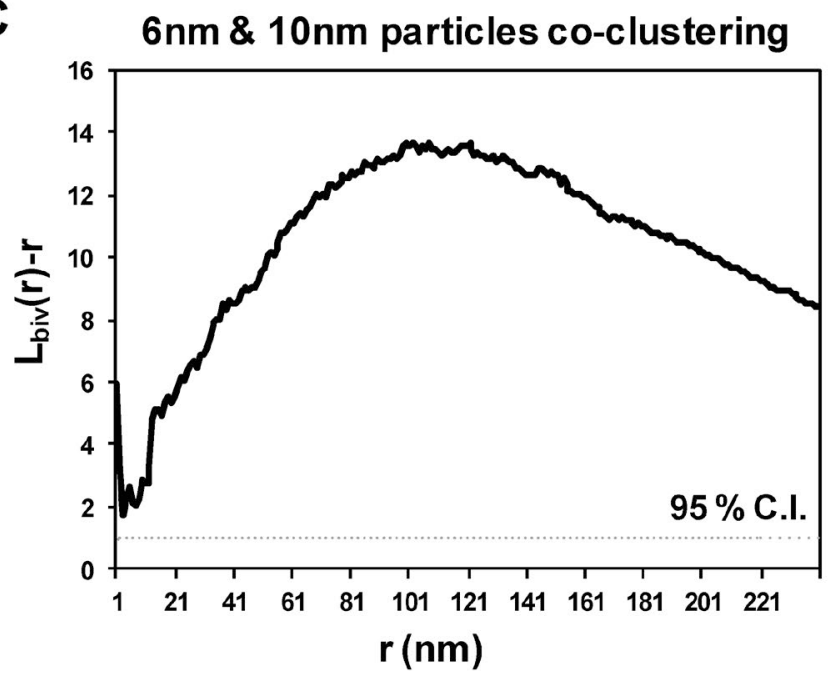

D GM1 (6) \& Actin (10)

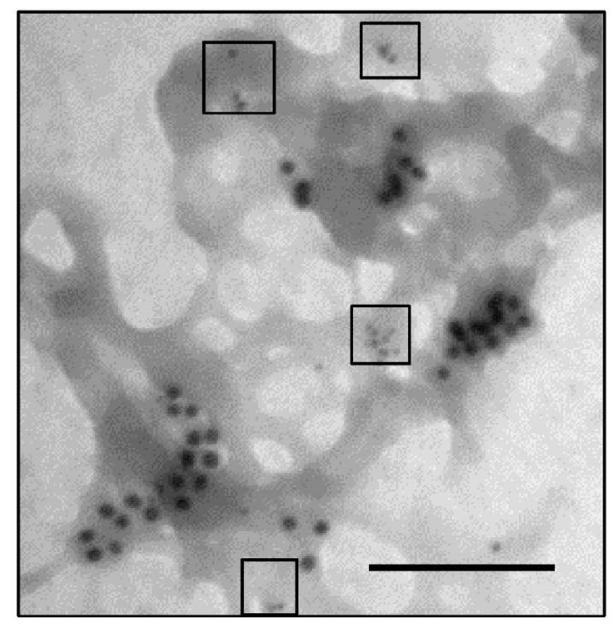

E GM1 (6), S100A10 (10) \& AnxA2 (15)

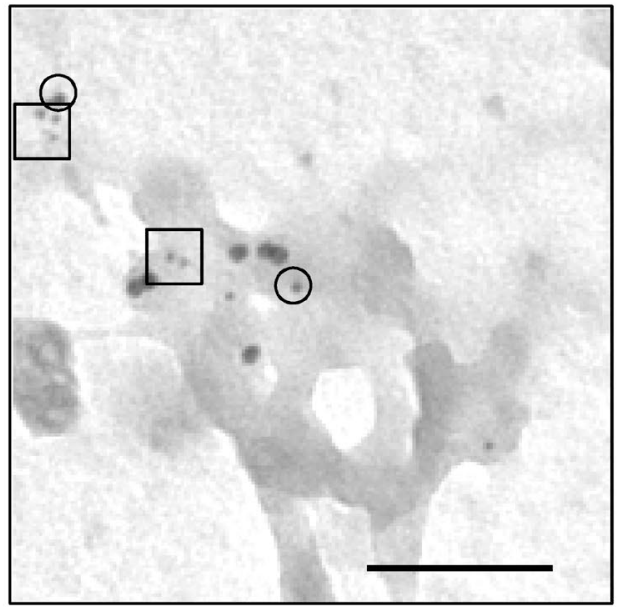

F GM1 (6), Actin (15) \& Synt (10)

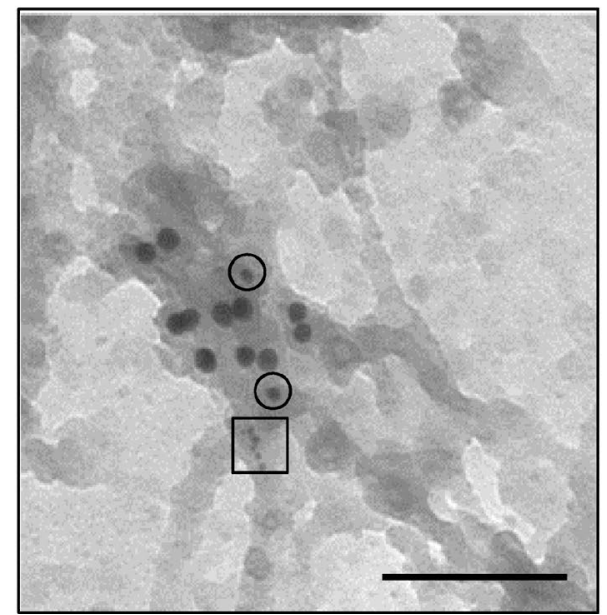

Figure 4. GM1-enriched domains formed at the plasma membrane in nicotine-stimulated cells contain the AnxA2 tetramer, actin filaments, and SNARE proteins. (A and B) Double staining of AnxA2 (10 nm gold particles) and phalloidin (6 nm gold particles) on plasma membrane sheets prepared from unstimulated (A) and nicotine-stimulated cells (B). The right panel in B shows a higher magnification of the region delimited by the rectangle. Note that AnxA2 is also present on the docked granule surface (arrowhead). (C) Bivariate K-function analysis of double-labeled membranes ( $n=44$ images). Values of L(r)-r greater than the $95 \% \mathrm{Cl}$ indicated the significant colocalization of F-actin and AnxA2 in nicotine-stimulated chromaffin cells. (D) Spatial distribution of GM1 $16 \mathrm{~nm}$ gold particles, squares) and actin (10 nm gold particles) on the plasma membrane from a nicotine-stimulated cell. (E and F) Plasma membrane sheets from nicotine-stimulated cells stained for either GM1 (6 nm gold particles, squares)/S100A 10 (10 nm gold particles, circles)/AnxA2 (15 nm gold particles) or GMI (6 nm gold particles, squares)/actin (15 nm gold particles)/syntaxin (10 nm gold particles, circles). Bars, $100 \mathrm{~nm}$. 
A

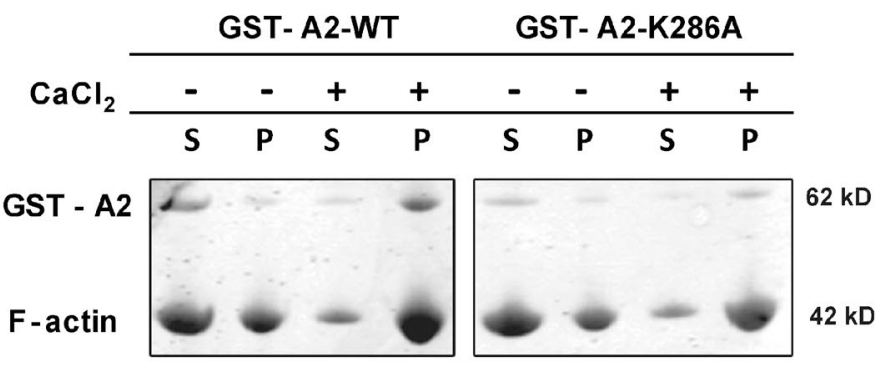

B
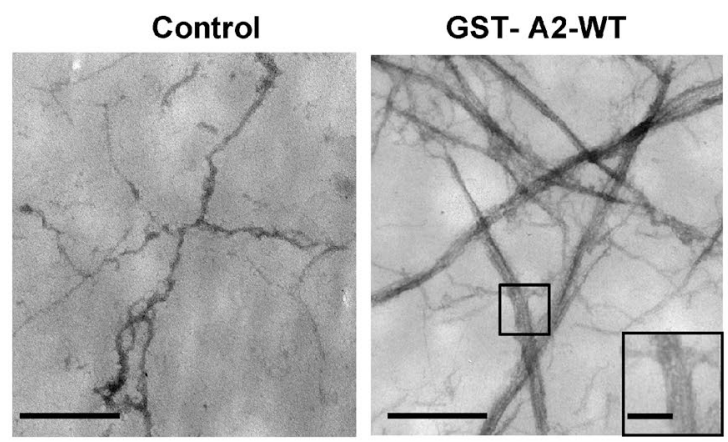

C

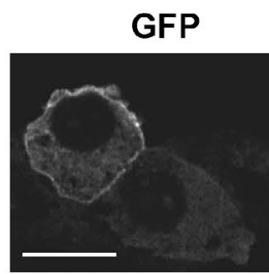

A2-WT

A2-K286A

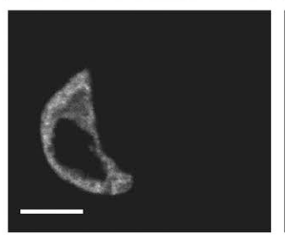

D
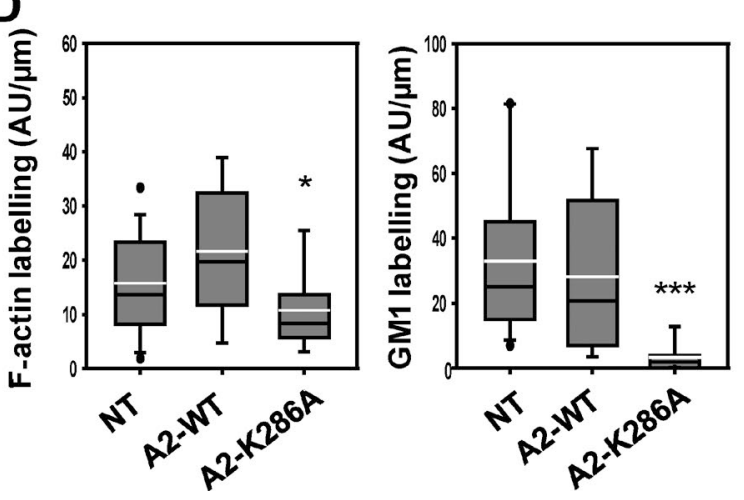

GST- A2-K286A

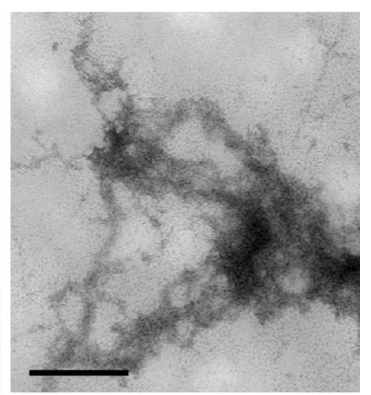

F-actin
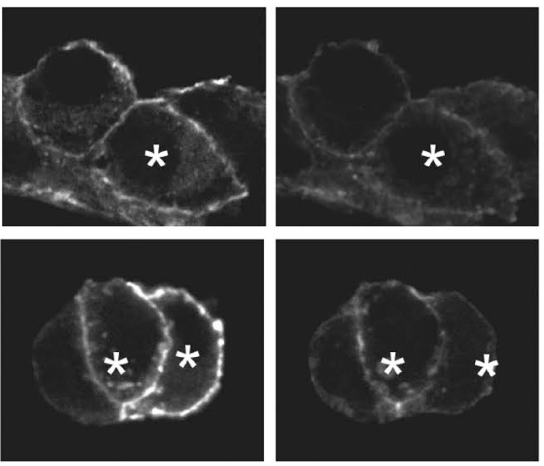

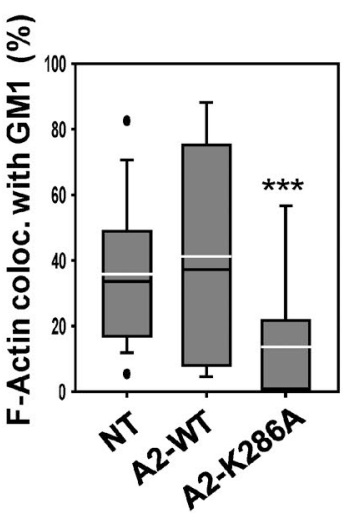

Figure 5. The actin-bundling activity of AnxA2 is linked to the formation of GMI-enriched domains in stimulated cells. (A) F-actin binding assay of recombinant GST-AnxA2 WT and GSTAnxA2 K286A in the absence and presence of calcium. Purified recombinant AnxA2 proteins fused with GST $(4 \mu M)$ were incubated with preformed actin filaments $(18 \mu \mathrm{M})$ for $30 \mathrm{~min}$ at room temperature. After low-speed centrifugation, the supernatant $(\mathrm{S})$ and pellet $(\mathrm{P})$ were collected and separated on a $4-20 \%$ SDSPAGE-gel. (B) Electron microscopic visualization of recombinant AnxA2/F-actin aggregates. Before centrifugation, a $5-\mu$ aliquot was spread on electron grids and prepared for electron microscopy. The inset shows a higher magnification of the region delimited by the square. (C) Cells expressing AnxA2-WT-GFP or AnxA2K286A-GFP were stimulated with $59 \mathrm{mM} \mathrm{K}^{+}$in the presence of fluorescent cholera toxin to visualize GMl-enriched domains, then fixed and stained with TRITC-phalloidin. Confocal images were recorded in the same optical section. Asterisks indicate nontransfected cells. (D) Semiquantitative analysis of cholera toxin (GMI) and F-actin labeling in nicotine-stimulated cells expressed in arbitrary units $( \pm S E M ; n=20)$. Statistical significance for medians (black line) was determined using a Mann-Whitney test. Asterisks indicate statistical significance ${ }^{*}, \mathrm{P}<$ $0.05 ; * *, P<0.001$ ) and the white lines represent the means. Similar results were obtained on three culture preparations. Bars: $(B$, main panels) $500 \mathrm{~nm}$; (B, inset) $100 \mathrm{~nm}$; (C) $10 \mu \mathrm{m}$. number of docked granules was reduced by nearly $70 \%$ in stimulated cells expressing AnxA2-K286A. This decrease was in the same range as the reduction of amperometric events observed in AnxA2-K286A-expressing cells (Fig. 7 B). The tomogram side view of a docked granule in cells expressing AnxA2-K286A revealed a disorganization of actin on the granule, an absence of actin bundles connecting granules to the plasma membrane, and no positive curvature of the plasma membrane under the docked granule (Fig. 9 B). Additionally, in chromaffin cells treated with WA, there was an increase in the number of docked granules (Fig. 9), in line with the increase in the number of amperometric events (Fig. 7 A). Altogether, these results strongly reinforce the idea that AnxA2 promotes the formation of actin bundles that anchor secretory granules to the plasma membrane and regulate the kinetics of fusion.

\section{Discussion}

AnxA2 is a prominent and well-studied member of the annexin family of $\mathrm{Ca}^{2+}$-dependent membrane-binding proteins known to be involved in several cellular processes including secretion 
A
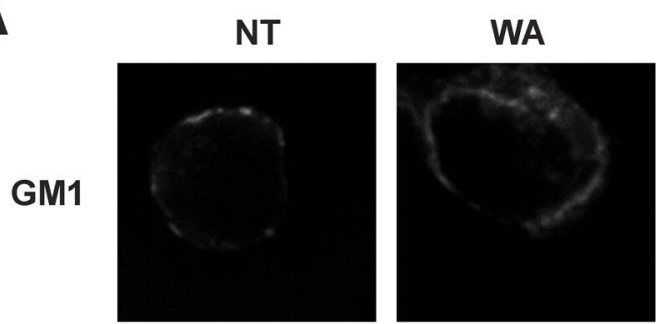

F-actin

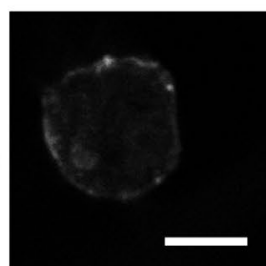

C

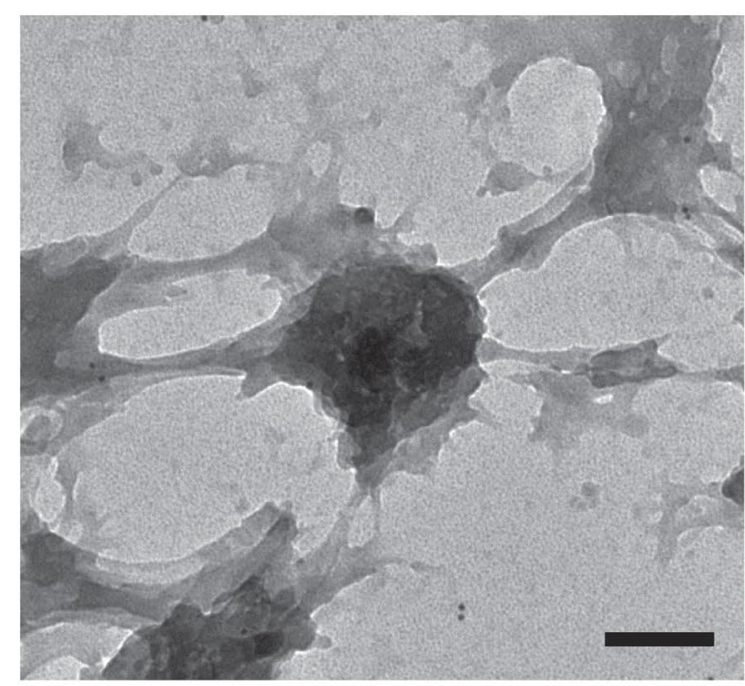

B

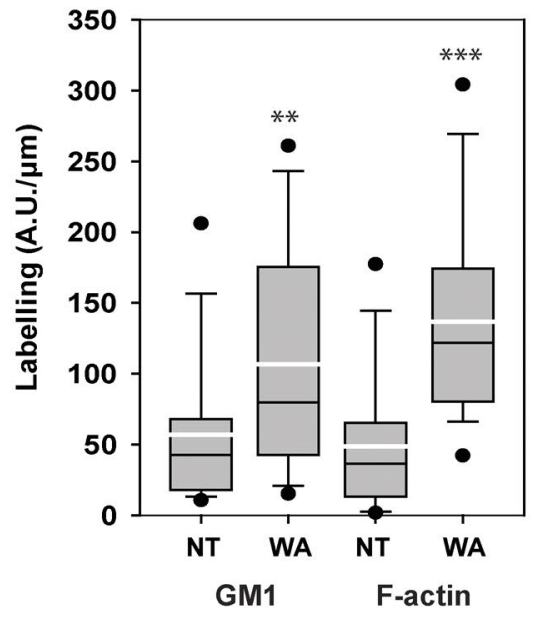

D

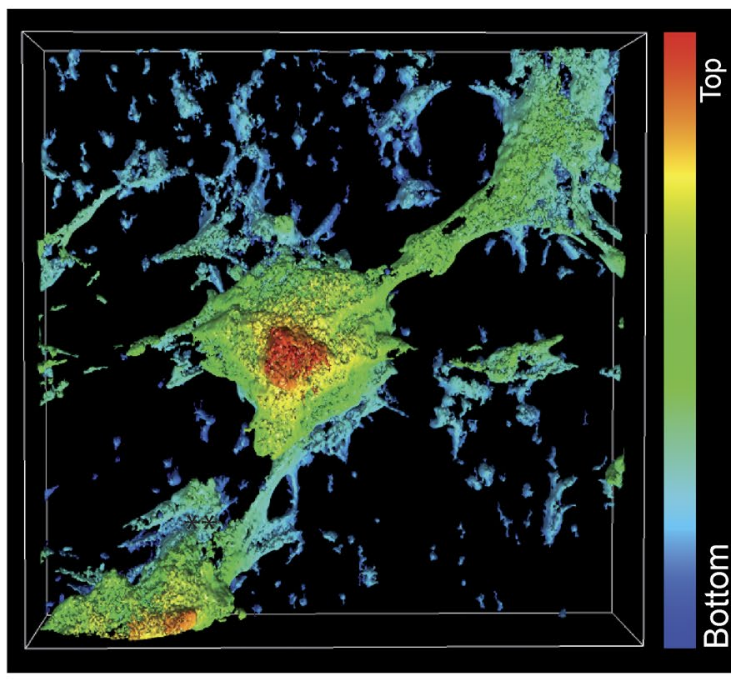

E

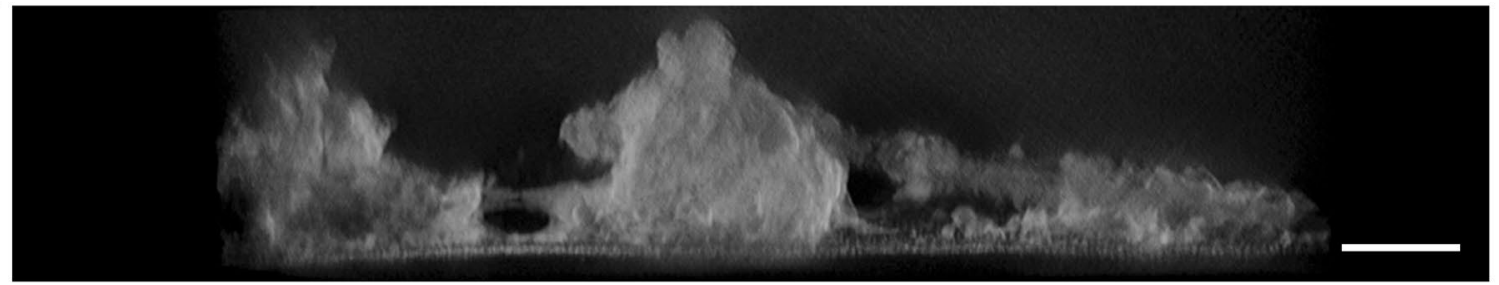

F

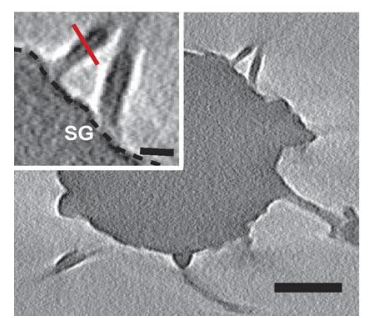

G

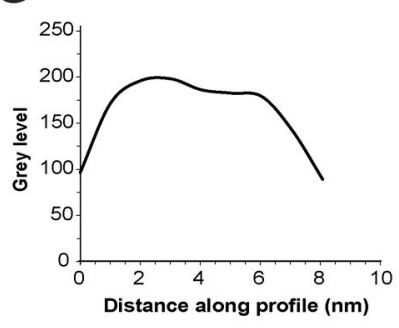

H

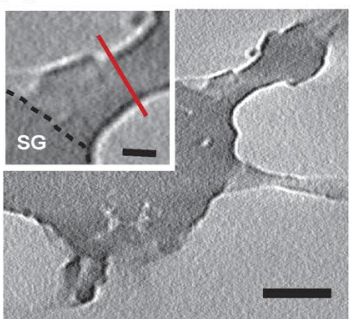

I

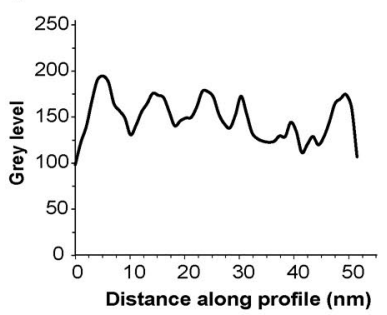

Figure 6. WA stimulates the formation of GMI-enriched domains and thickens actin bundles connecting secretory granules to the plasma membrane in nicotine-stimulated cells. (A) Confocal micrographs of cells treated for $1 \mathrm{~h}$ with $3 \mu \mathrm{M}$ WA and stimulated with $10 \mu \mathrm{M}$ nicotine in the presence of cholera toxin. Cells were then fixed and labeled with rhodamine-conjugated phalloidin to visualize F-actin. (B) Semiquantitative analysis of cholera toxin and F-actin labeling expressed in arbitrary units $( \pm S E M ; n=15)$. Statistical significance for medians (black line) was determined using a Mann-Whitney test. The asterisks indicate statistical significance $\left({ }^{*}, \mathrm{P}<0.01 ;{ }^{* *}, \mathrm{P}<0.001\right)$ and the white lines represent the means. Similar results were obtained in two independent experiments performed on two culture preparations. (C) Electron micrographs of plasma membrane sheets prepared from nicotine-stimulated 
in many cell types (Bharadwaj et al., 2013). Most of its cellular functions are related to the calcium-dependent phospholipid-binding properties. Yet, AnxA2 also displays an actin-binding and bundling activity whose functional importance within cells remains poorly understood. In neuroendocrine chromaffin cells, AnxA2 translocates from the cytosol to the plasma membrane upon cell stimulation, promoting the formation and/or stabilizing the lipid microdomains required for structural and spatial organization of the exocytotic machinery (Chasserot-Golaz et al., 2005; Umbrecht-Jenck et al., 2010). In this study, we show that AnxA2-mediated actin bundles form GM1-enriched lipid microdomains at the plasma membrane, where syntaxin- 1 and docked granules were observed. At these presumed exocytotic sites, actin bundles coat and anchor granules to the plasma membrane. Functional studies performed using amperometry indicate that the AnxA2-dependent actin-bundling activity controls the number of docked granules and exocytotic events, and somehow provides a driving force that promotes fusion pore expansion and granule cargo release. This is the first report describing the $3 \mathrm{D}$ actin cytoarchitecture at the site of exocytosis, and establishing a role for the AnxA2-dependent actin bundling activity in the pathway underlying secretion.

\section{Actin bundles anchor docked granules to the plasma membrane}

Actin is well known to influence some of the many steps leading to exocytosis in neuroendocrine cells. Until recently, the widely accepted view was that the cortical actin network acts essentially as a physical barrier to prevent granule access to the cell surface. However, such a housekeeping function for actin is inconsistent with several functional studies suggesting an active role for actin in the exocytotic machinery (for reviews see Malacombe et al., 2006; Gutiérrez, 2012). For instance, actin filaments in association with myosins participate in the transport and guiding of secretory granules to their fusion sites (Papadopulos et al., 2013a,b; Tomatis et al., 2013). Actin has also been proposed to play a positive role in late stages of exocytosis by controlling the fusion pore and specifying kiss and run versus full exocytosis (Gutiérrez, 2012) and/or by directly expelling secretory content (Miklavc et al., 2012). Thus, it is now clear that exocytosis cannot occur without a minimal actin cytoskeletal structure, although the presence and organization of actin at the sites of exocytosis has never been observed before and has been highly speculative. Here, we provide the first detailed electron tomography analysis of the fine structure of actin filaments present at exocytotic sites under close-to-native conditions. Images of the 3D arrangement of the cytoskeleton entrapping secretory granules docked at the plasma membrane revealed that actin filaments coat docked granules and form bundles connecting granules to the plasma membrane. Our results support the notion that the F-actin cytoarchitecture organizes different components of the secretory machinery to shape exocytosis in neuroendocrine cells (Gutiérrez, 2012). The origin of this actin-based docking machinery in stimulated cells is not known. The actin-bundling activity of AnxA2 appears to account, at least in part, for the actin bundles anchoring granules to the plasma membrane. However, actin filaments may also be synthesized de novo onsite by local adaptor molecules described to be present at exocytotic sites such as N-Wasp and Arp2/3 (Gasman et al., 2004) or Rab27A and MyRip (Desnos et al., 2003), or represent residual polymerized actin persisting at granule docking sites after secretagogue-induced cortical actin rearrangements.

\section{Actin-bundling activity of AnxA2 is required for the formation of GM1-enriched granule docking sites}

GM1/cholesterol/PI(4,5) $\mathrm{P}_{2}$-enriched lipid microdomains are required for efficient SNARE-mediated granule docking and fusion with the plasma membrane (Aoyagi et al., 2005; Lang, 2007). Yet, the lateral diffusion rate of cholesterol and PI(4,5) $\mathrm{P}_{2}$ within the lipid bilayer is probably much faster than their local biosynthesis rate, suggesting that lipid microdomain clustering and formation depend on diffusion barriers provided by proteins. AnxA2 has been proposed for this putative role because the formation of $\mathrm{GM} 1 /$ cholesterol/PI $(4,5) \mathrm{P}_{2}$ clusters in stimulated chromaffin cells requires the translocation of AnxA2 to the plasma membrane (Chasserot-Golaz et al., 2005) and AnxA2 has been found to be recruited to SNARE clusters at the plasma membrane (Umbrecht-Jenck et al., 2010). However, although the protein has the physical properties necessary for organizing lipid clusters (Drücker et al., 2013), mechanisms by which AnxA2 forms a specific lipid environment at granule docking sites need to be elucidated. We showed here that, in nicotine-stimulated cells, the actin-bundling activity of AnxA2 promotes the formation of GM1-enriched microdomains at the plasma membrane, increases the number of morphologically docked granules at the plasma membrane, and controls the number of individual exocytotic events. Thus, AnxA2-dependent actin bundles participate in the spatial organization of the plasma membrane, providing active sites for secretory granule docking and exocytotic fusion. These observations highlighting new functions for the actin cytoskeleton in regulated exocytosis are consistent with a recent report showing that F-actin interferes with SNAP-25 patch mobility and significantly influences the probability of fusion of associated secretory granules (Torregrosa-Hetland et al., 2013). Yet, AnxA2-mediated actin bundles could also promote docking through the formation of the specific lipid environment required for SNARE complex formation or stabilize granules captured by minimal tethering machinery and prevent them from rapidly undocking (Toonen et al., 2006). Understanding the precise mechanism by which AnxA2-generated actin bundles contribute to the docking machinery and thereby accelerate vesicle fusion is clearly the next challenge.

and WA-treated cells labeled with anti-actin antibodies and immunogold. (D) 3D model of the same secretory granule showing the bundling effect of WA on the actin network anchored to the granule surface. False colors were applied using a color-coded surface related to the topographic height on the right (Video 2). (E) Clipping plane of the side view of the isosurface representation of a tomogram showing an increase in the actin network anchored to the granule surface in a WA-treated cell. (F-l) Central tomographic section of a docked secretory granule and corresponding enlargement (inset, $2.5 \times$ zoom) showing anchored actin filaments and the granule surface marked with a dotted black line. Graphs (G and I) represent a plot profile along the red line perpendicular to the actin filament. Images were obtained from control (F) and WA-treated $(H)$ cells stimulated with nicotine. Plot profiles presented are representative of several measurements ( $n=15$ for each plot profile) from different tomograms ( $n=3$ for each conditions). Individual 10 -nm actin filaments anchored granules in control cells, whereas large actin bundles consisting of at least five actin filaments were observed in WA-treated cells. Bars: (A) 5 um; (C) $200 \mathrm{~nm}$; (E, F and H, main panels) $100 \mathrm{~nm}$; ( $F$ and H, insets) $25 \mathrm{~nm}$. 

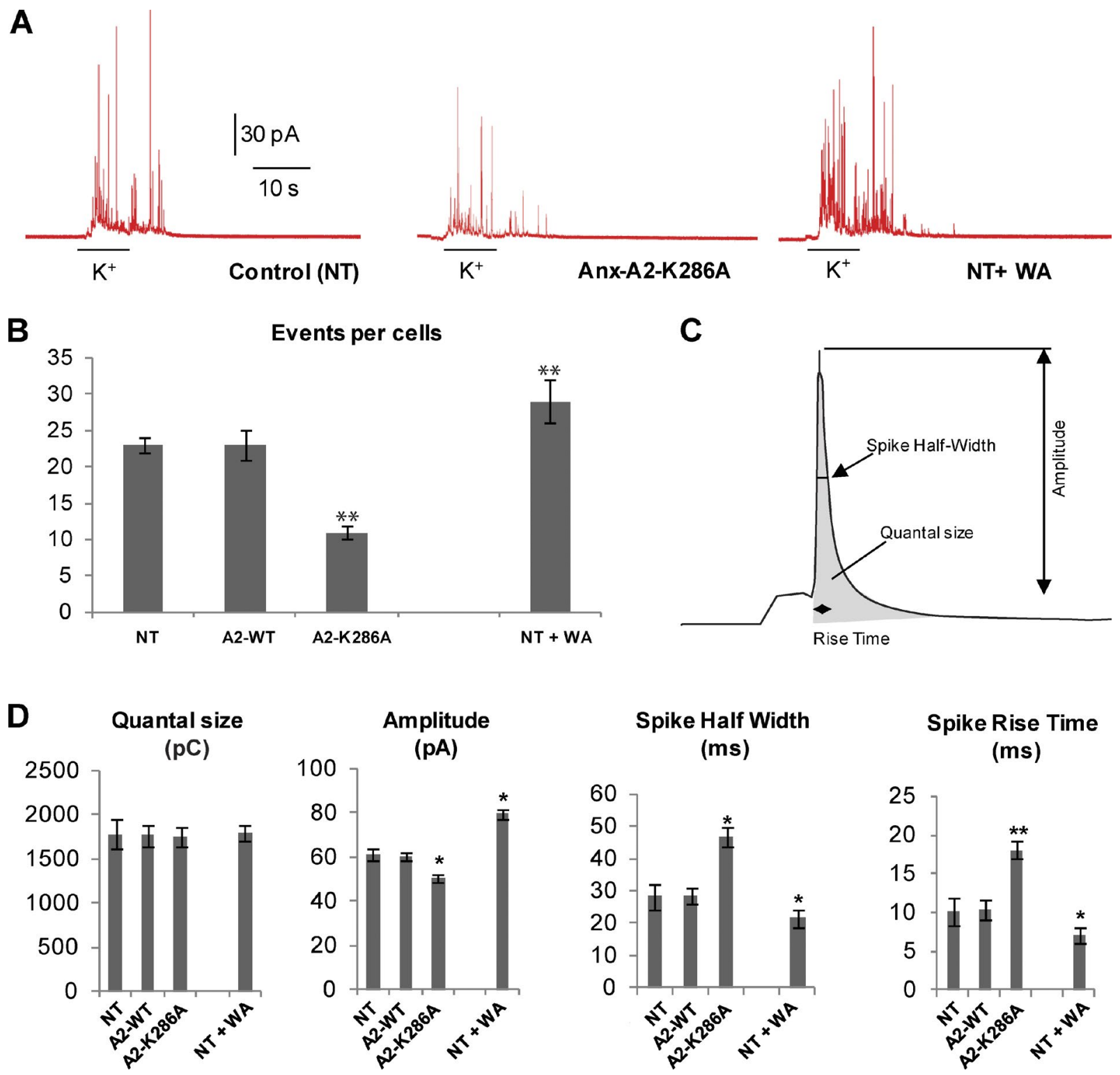

Figure 7. The actin-bundling activity of AnxA2 is involved in granule recruitment and fusion. Chromaffin cells were stimulated with a local application of $100 \mathrm{mM} \mathrm{KCl}$ for $10 \mathrm{~s}$, and catecholamine secretion was monitored using carbon fiber amperometry. Control release was measured in nontransfected cells from the same culture dish. (A) Typical amperometric recordings obtained in nontransfected cells (NT), cells expressing AnxA2-K286A-GFP, and cells treated for $1 \mathrm{~h}$ with $5 \mu \mathrm{M}$ WA. (B) The number of amperometric spikes per cell recorded in nontransfected cells (NT), cells transfected with AnxA2-WT-GFP (A2-WT) or AnxA2-K286A-GFP (A2-K286A), or WA-treated cells (NT+WA). Results represent the mean \pm SD (error bars) from 25-55 cells. (C) Schema showing the different spike parameters of the amperometric response (means $\pm \mathrm{SEM}$ ) measured in $\mathrm{D} .{ }^{*}, \mathrm{P}<0.05 ;{ }^{*}, \mathrm{P}<0.01$.

\section{Actin-bundling activity of AnxA2 affects the kinetics of catecholamine release}

Amperometric recordings revealed that the AnxA2 F-actin-bundling activity was not only linked to the formation of exocytotic platforms and the number of morphological docked granules, but also to the kinetics of the exocytotic event itself. Indeed, the AnxA2 actin-bundling activity was correlated with the spike rise time, amplitude, and half-width, suggesting a possible link between the AnxA2-induced actin architecture and the flux of catecholamine release. AnxA2 contains a stretch of nine amino acids (residues 286-294) in its carboxy-terminal core that is remarkably similar to the actin-binding site of the myosin S-1 heavy chain (Jones et al., 1992). In nonneuronal cell types, actin coat contraction and myosin II have been proposed to compress fused granules for active extrusion of nonsoluble, bulky granu- lar contents (Miklavc et al., 2012). In chromaffin cells, myosin II inhibition increases amperometric spike half-widths without changing quantal size (Berberian et al., 2009). Thus, to some extent, the role of AnxA2 seems to be close to that of myosin II. However, AnxA2 actin-bundling activity also affected the charge and lifetime of PSF, suggesting a functional link between AnxA2/actin and the characteristics of the early fusion pore, a role that has not been proposed for myosin II (Berberian et al., 2009). In fact, tension in the membrane is thought to favor fusion pore formation or expansion (Monck et al., 1991). By providing actin filament bundles at granule docking sites, AnxA2 could induce membrane deformation, possibly reflected by the positive curvature of the plasma membrane observed here under docked granules (Fig. 3 A). Furthermore, cholesterol depletion has been shown to decrease PSF duration (Cookson 

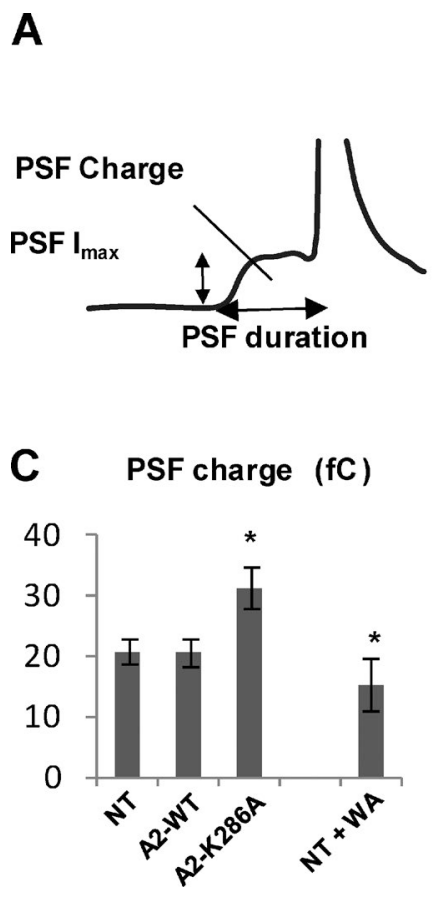

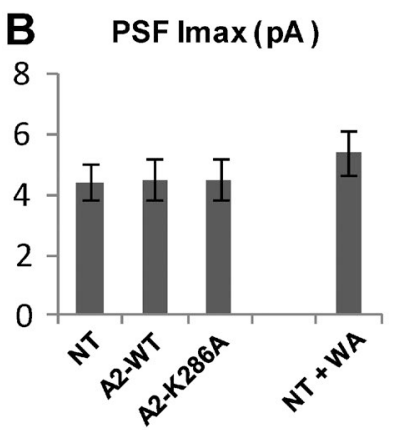

D PSF duration (ms)

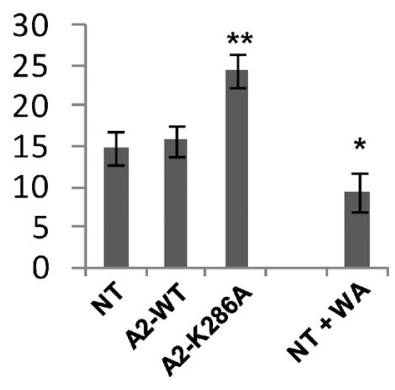

Figure 8. The actin-bundling activity of AnxA2 modulates the formation of the initial fusion pore. (A) Schema showing the parameters of the PSF signal measured in $B, C$, and D panels. NT, nontransfected cells; A2-WT, cells transfected with AnxA2-GFP WT; A2-K286A, cells transfected with AnxA2-K286A-GFP; NT + WA, cells treated for $1 \mathrm{~h}$ with $5 \mu \mathrm{M}$ WA. Data are expressed as mean \pm SEM (error bars). ${ }^{*}, \mathrm{P}<0.05 ;{ }^{*}, \mathrm{P}<0.01$.

et al., 2013), suggesting that AnxA2 could also regulate fusion pore formation through its lipid segregation activity (Drücker et al., 2013) and its capacity to organize the GM1/cholesterol/ $\mathrm{PI}(4,5) \mathrm{P}_{2}$-enriched exocytotic sites at the plasma membrane (Chasserot-Golaz et al., 2005; Umbrecht-Jenck et al., 2010).

To conclude, AnxA2 plays a central role in neuroendocrine secretion, coordinating lipid microdomain formation, both spatially and temporally, with actin filament bundling necessary for efficient fusion and granule cargo release. The AnxA2-induced microdomains are likely to be important for many fundamental biological processes requiring membrane dynamics ranging from cell differentiation to cell migration and secretion (Hitchcock et al., 2014; Astro and de Curtis, 2015).

\section{Materials and methods}

\section{Antibodies and reagents}

Rabbit polyclonal antibodies directed against AnxA2 (p36) purified from bovine aorta were diluted 1:200 (a gift from J.C. Cavadore, Institut National de la Santé et de la Recherche Médicale U-249, Paris, France). Rabbit polyclonal antibodies directed against DBH (EC.1.14.17.1) purified from bovine chromaffin granules were diluted 1:75 to specifically label secretory granules in chromaffin cells (Chasserot-Golaz et al., 1996). Mouse monoclonal antibodies directed against syntaxin, TRITC-conjugated phalloidin, and Latrunculin B were from Sigma-Aldrich. Mouse monoclonal antibodies directed against GFP (clones 7.1 and 13.1) were from Roche. Secondary goat anti-rabbit and anti-mouse antibodies and streptavidin coupled to Alexa Fluor conjugates (488, 555 , or 647) or gold particles were from Molecular Probes (Invitrogen) and Aurion, respectively. Fluorescent cholera toxin B subunit coupled

to Alexa Fluor 633 or 555 were from Molecular Probes (Thermo Fisher Scientific), and WA was from Calbiochem inhibitors (EMD Millipore).

\section{Chromaffin cells}

Chromaffin cells were isolated from fresh bovine adrenal glands. In brief, glands were perfused with calcium-free Locke's solution (140 mM NaCl, $4.7 \mathrm{mM} \mathrm{KCl}, 1.2 \mathrm{mM} \mathrm{KH}_{2} \mathrm{PO}_{4}, 1.2 \mathrm{mM} \mathrm{MgSO}_{4}$, $11 \mathrm{mM}$ glucose, $0.56 \mathrm{mM}$ ascorbic acid, and $15 \mathrm{mM}$ Hepes, $\mathrm{pH} 7.5$ ) containing $0.1 \%$ Clostridium histolyticum collagenase (Boehringer Ingelheim) and $0.5 \%$ BSA. Then, the medullae were dissected and further dissociation of chromaffin cells was achieved by passing the cells through a nylon sieve $(120 \mu \mathrm{m}$ pore size). Cells were collected in calcium-free Locke's solution and purified on self-generating Percoll gradients and maintained in culture as described previously (Bader et al., 1986). To induce exocytosis, chromaffin cells were washed twice with Locke's solution ( $140 \mathrm{mM} \mathrm{NaCl}, 4.7 \mathrm{mM} \mathrm{KCl}, 2.5 \mathrm{mM} \mathrm{CaCl}_{2}$, $1.2 \mathrm{mM} \mathrm{KH}_{2} \mathrm{PO}_{4}, 1.2 \mathrm{mM} \mathrm{MgSO}_{4}, 11 \mathrm{mM}$ glucose, $0.56 \mathrm{mM}$ ascorbic acid, $0.01 \mathrm{mM}$ EDTA, and $15 \mathrm{mM}$ Hepes, $\mathrm{pH} 7.5$ ) then stimulated with Locke's solution containing $20 \mu \mathrm{M}$ nicotine or depolarizing solution (Locke's solution adjusted to $59 \mathrm{mM} \mathrm{K}^{+}$).

\section{DNA constructs and cell transfection}

Human recombinant AnxA2 was inserted in BglII- and SalI-digested pEGFP-N3 (Rescher et al., 2000); this plasmid was provided by V. Gerke (Institute for Medical Biochemistry, Zentrum für Molekularbiologie der Entzündung, University of Munster, Germany). AnxA2K286A-GFP mutant was generated using a QuikChange mutagenesis kit (Agilent Technologies) and the following oligonucleotides (forward, 5'-AAGGGGACGCGAGATGCGGTCCTGATCAGAATC-3'; reverse, 5'-GATTCTGATCGAGACCGCATCTCGCGTCCCCTT-3'; bold nucleotides indicate changes in the sequence compared to WT). AnxA2 WT and AnxA2-K286A were subcloned in BglII- and SaII-digested pGEX4T1. Constructs were verified by DNA sequencing (GATC Biotech). GST-AnxA2 WT and GST-AnxA2-K286A were produced in BL21 E. coli and purified on glutathione-Sepharose beads (GE Healthcare) as described previously (Vitale et al., 1996). The purity was estimated at $98 \%$ by Coomassie blue staining of SDS-PAGE gels. Plasmids $(3 \mu \mathrm{g})$ were transfected into chromaffin cells $\left(5 \times 10^{6}\right.$ cells $)$ by electroporation (Amaxa Nucleofactor systems; Lonza) according to the manufacturer's instructions. Electroporated cells were immediately recovered in warm culture medium and plated onto fibronectin-coated glass coverslips. Experiments were performed $48 \mathrm{~h}$ after transfection.

\section{In vitro F-actin binding experiments}

The F-actin-bundling activity of recombinant GST-AnxA2 (WT and K286A) was tested in vitro using the nonmuscle actin binding protein Spin-Down Biochem kit (catalogue no. BK013; Cytoskeleton, Inc.). F-actin binding proteins cosediment with actin aggregates in the pellet $(14,000 \mathrm{~g}, 1 \mathrm{~h})$. The distribution of the protein in the supernatants and pellets was analyzed by SYPRO Orange staining on SDS-PAGE gels (Invitrogen, Thermo Fisher Scientific).

Formation of actin bundles was assessed by electron microscopy (Ikebuchi and Waisman, 1990). Before centrifugation, aliquots $(5 \mu \mathrm{l})$ were spread on electron grids and negatively stained with $1 \%$ uranyl acetate, and aggregates were observed using a transmission electron microscope (7500; Hitachi).

\section{Immunofluorescence and confocal microscopy}

For immunocytochemistry, chromaffin cells, grown on fibronectin-coated glass coverslips, were fixed and labeled as described previously (Chasserot-Golaz et al., 1996). GM1 was labeled on live chromaffin cells incubated for $10 \mathrm{~min}$ with $8 \mu \mathrm{g} / \mathrm{ml}$ fluorescent cholera 
A

A A2-WT
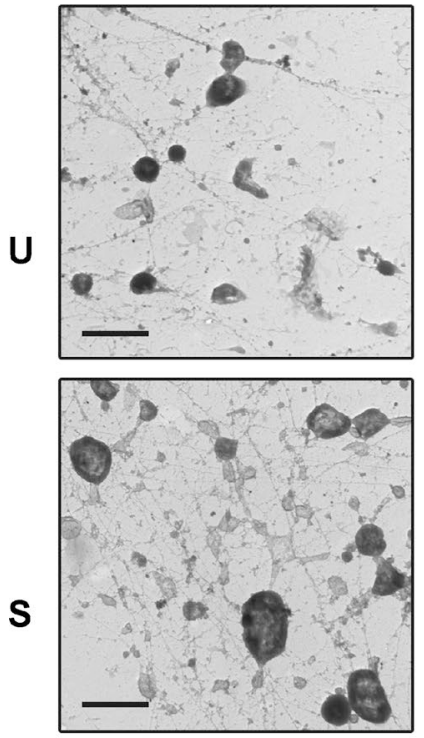

B

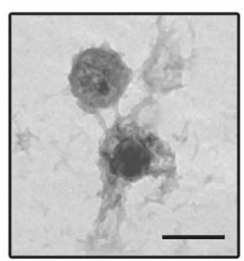

A2-K286A
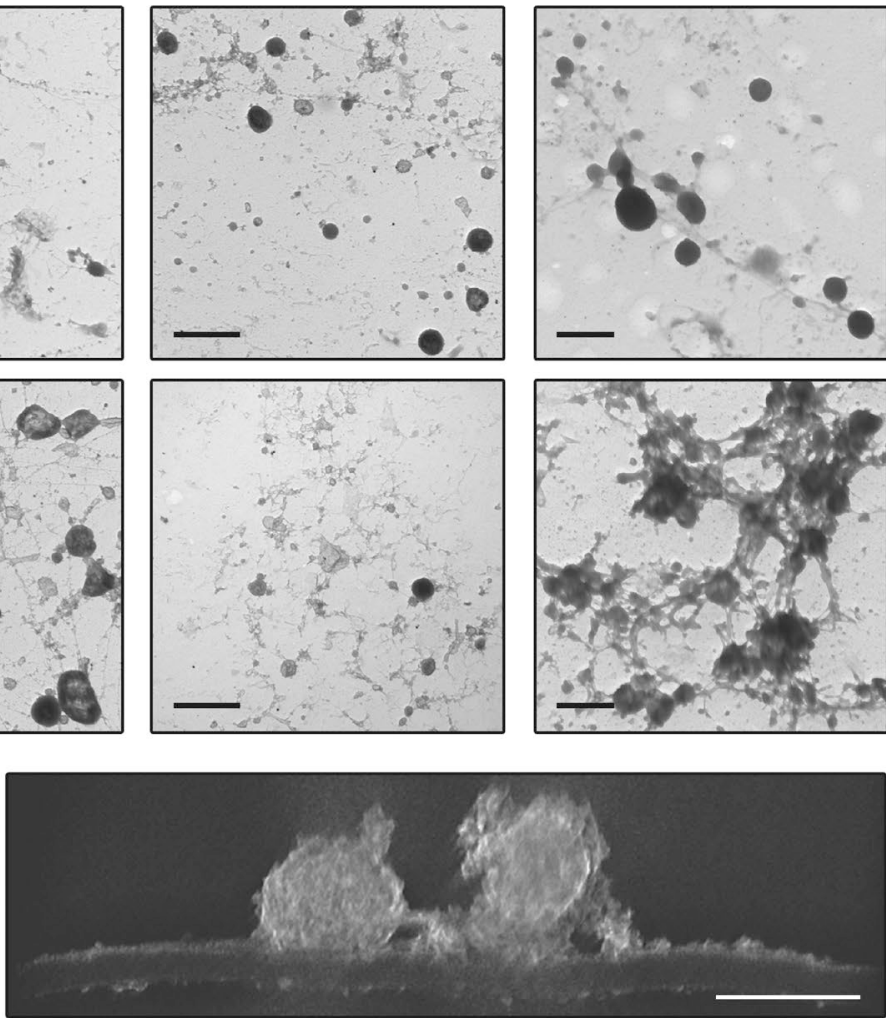

C

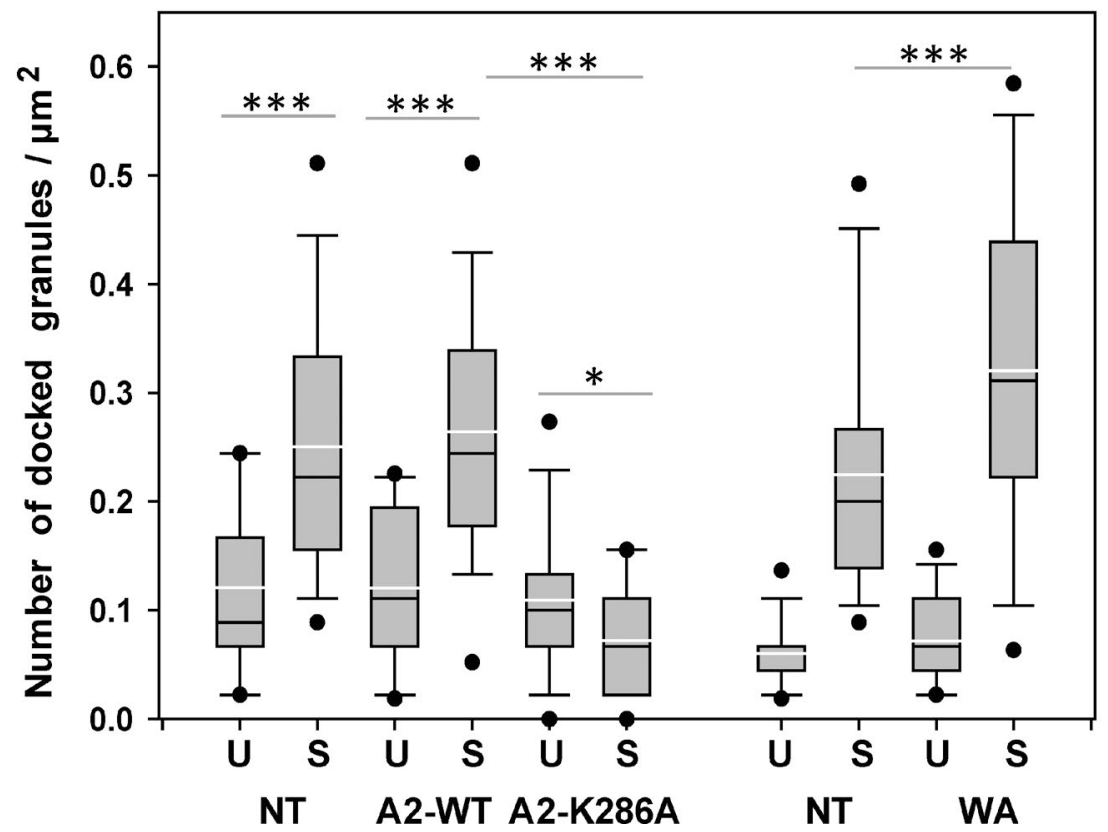

Figure 9. AnxA2 forms the actin bundles that anchor the secretory granules at the plasma membrane during exocytosis. (A) Electron micrograph plasma membrane sheets prepared from unstimulated or stimulated cells transfected with AnxA2-WT-GFP (A2-WT) or AnxA2-K286A-GFP (A2-K286A), or nontransfected cells treated with WA (NT+WA). Transfected cells were labeled with anti-GFP antibodies revealed with $25 \mathrm{~nm}$ gold particles. Bars, $500 \mathrm{~nm}$. (B) TEM image at zero tilt of a secretory granule docked on the plasma membrane of a cell transfected with AnxA2K286A-GFP (left) and the clipping plane of the side view of the isosurface representation of the tomogram (right). Bars, $200 \mathrm{~nm}$. (C) The number of granules morphologically docked on plasma membrane sheets of unstimulated (U) and stimulated (S) cells, nontransfected cells (NT), cells transfected with AnxA2-WTGFP (A2-WT) or AnxA2-K286A-GFP (A2K286A), or cells treated with WA (NT+WA). Results indicate \pm SEM from 25-50 images. Asterisks indicate statistical significance ${ }^{* * *}$, $\mathrm{P}<0.001$ ) for medians (black line) determined using a Mann-Whitney test, the white lines represent the means. Images were acquired from three different culture preparations. toxin B subunit (coupled with Alexa Fluor 633 or Alexa Fluor 555) in Locke's solution with or without $20 \mu \mathrm{M}$ nicotine. The transient accessibility of DBH to the plasma membrane of chromaffin cells was tested by incubating cells for $10 \mathrm{~min}$ in Locke's solution containing $20 \mu \mathrm{M}$ nicotine and anti-DBH antibodies diluted to 1:75. F-actin was stained with TRITC-conjugated phalloidin $(0.5 \mu \mathrm{g} / \mathrm{ml})$ for $15 \mathrm{~min}$ in the dark at room temperature. Cells were then mounted in Moviol (Hoechst) and visualized using a confocal microscope (SP5II; Leica) equipped with a Plan-Apochromat oil immersion objective lens (63×, NA 1.4). The proportion of colocalization was estimated from the double-labeled pixels using ICY software (http://icy.bioimageanalysis.org/). The amount of cholera toxin or TRITC-phalloidin associated with the plasma membrane was measured and expressed as the mean fluorescence intensity normalized to the corresponding surface area, and divided by the total perimeter of each cell. This allowed a quantitative cell-to-cell comparison of the fluorescence detected in cells.

\section{Amperometry}

Bovine chromaffin cells were transfected with plasmids encoding GFPtagged AnxA2 WT or mutant and seeded in Petri dishes. After 48 h, 
cells were washed with Locke's solution and catecholamine secretion was evoked by applying $100 \mathrm{mM} \mathrm{K}^{+}$in Locke's solution without ascorbic acid for $10 \mathrm{~s}$ to single cells by means of a glass micropipette positioned at a distance of $30-50 \mu \mathrm{m}$ from the cell. Electrochemical measurements of catecholamine secretion were performed using 5 - $\mu \mathrm{m}$-diameter carbon fiber electrodes (ALA Scientific Instruments) held at a potential of $650 \mathrm{mV}$ compared with the reference electrode $(\mathrm{Ag} / \mathrm{AgCl})$ and approached closely to the recorded cells essentially as described previously (Poëa-Guyon et al., 2013). Amperometric recordings were performed with an amplifier (AMU130; Radiometer Analytical), sampled at $5 \mathrm{kHz}$, and digitally low pass filtered at $1 \mathrm{kHz}$. Analysis of amperometric recordings were performed with a macro (obtained and freely available from R. Borges laboratory [Analysis program 3.3], written for Igor software; WaveMetrics), allowing automatic spike detection and extraction of spike parameters (Segura et al., 2000). The number of amperometric spikes was counted as the total number of spikes with an amplitude $>5 \mathrm{pA}$ and time-to-peak $>35 \mathrm{~ms}$ within $60 \mathrm{~s}$.

\section{Plasma membrane sheet preparation and scanning for electron microscopy}

Cytoplasmic face-up membrane sheets were prepared and processed as described previously (Umbrecht-Jenck et al., 2010). In brief, carbon-coated Formvar films on nickel electron grids were inverted onto unstimulated or nicotine-stimulated chromaffin cells incubated with biotin-conjugated cholera toxin. To prepare membrane sheets, pressure was applied to the grids for $20 \mathrm{~s}$, then grids were lifted so that the fragments of the upper cell surface adhered to the grid. These membrane portions were fixed in $2 \%$ paraformaldehyde for $10 \mathrm{~min}$ at $4^{\circ} \mathrm{C}$, immediately after cell stimulation and sheet preparation, which required $<30$ s. After blocking in PBS with $1 \%$ BSA and $1 \%$ acetylated BSA, the immune labeling was performed and revealed with $10 \mathrm{~nm}$ or $15 \mathrm{~nm}$ gold particle-conjugated secondary antibodies and 6-nm particle-conjugated streptavidin. These membrane portions were fixed in $2 \%$ glutaraldehyde in PBS, postfixed with $1 \% \mathrm{OsO}_{4}$, dehydrated in a graded ethanol series, treated with hexamethyldisilazane (Sigma-Aldrich), airdried, and studied using a transmission electron microscope (7500; Hitachi) equipped with camera (C4742-51-12NR; Hamamatsu Photonics).

Granules were counted on random TEM images of plasma membrane sheets ( $n=25-50$ images of $45 \mu \mathrm{m}^{2}$ of plasma membrane). The data are expressed as number of granules $/ \mu \mathrm{m}^{2}$.

\section{Mapping gold particle distribution and analysis}

To map gold particle distribution, images of labeled plasma membrane sheets were digitized, and the coordinates of all gold particles in a given area were determined using an ImageJ plug-in (http://rsb.info.nih.gov/ $\mathrm{ij} /$ ) as described previously (Zhang et al., 2006a,b). To define spatial relationships of two different sizes of gold beads, Ripley's univariate K-function analysis was used. Analysis of the coordinates indicates whether the gold pattern is clustered, dispersed, or random. Colocalization of the two proteins was determined by analyzing the extent to which the two populations of gold particles were clustered with respect to each other using an Excel macro written in Visual Basic, provided by J.F. Hancock (Department of Integrative Biology and Pharmacology, University of Texas Medical School, Houston, TX)(Rotblat et al., 2004; Hancock and Prior, 2005). A macro is available as supplement S1.

\section{Electron tomography and image processing}

Tilt series were acquired on a transmission electron microscope (JEM-2100; JEOL) operated at $200 \mathrm{kV}$. Data were automatically acquired using digital micrograph software. Typically, the tilt ranged between -60 and +60 with $2^{\circ}$ angular increments. Images were recorded mainly at a nominal magnification of 10,000 on an Ultrascan $2 \mathrm{k} \times 2 \mathrm{k}$ CCD camera (Gatan) with defocus set to $-4 \mu \mathrm{m}$. Alignments and weighted back-projection-based reconstructions of raw tilt series, using anti-actin immunogold particles as fiducial markers, were computed with the IMOD software package (Kremer et al., 1996). Three-dimensional reconstructions were visualized with UCSF Chimera (Pettersen et al., 2004).

\section{Statistical analysis}

As specified in the figure legends, group data are presented as mean $( \pm$ SEM) or median, and were analyzed using a Mann-Whitney test. Asterisks in each box and whisker plot indicate statistical significance $\left(^{*}\right.$, $\mathrm{P}<0.05 ; * *, \mathrm{P}<0.01 ; * * *, \mathrm{P}<0.001)$.

\section{Online supplemental material}

Fig. S1 shows the distribution of GM1 and actin on plasma membrane sheets visualized by immunogold labeling and electron microscopy at a lower magnification $(70,000 \times)$. Video 1 shows a 3D representation of the cortical actin network surrounding the secretory granule docked at the plasma membrane of a nicotine-stimulated chromaffin cell. Video 2

Table 1. Characteristics of amperometric spikes and PSFs in transfected chromaffin cells

\begin{tabular}{|c|c|c|c|c|c|c|}
\hline Parameters analyzed & Control (NT) & A2 WT & A2 K286A & WA & $A 2 W T+W A$ & A2 K286A +WA \\
\hline Number of cells & 56 & 25 & 32 & 39 & 25 & 25 \\
\hline Number of spikes (total) & 1,322 & 551 & 358 & 1,136 & 702 & 304 \\
\hline Number of spikes per cell & $23 \pm 1$ & $22 \pm 2$ & $11 \pm 1$ & $29 \pm 3$ & $28 \pm 3$ & $12 \pm 1$ \\
\hline Number of spikes (analyzed) & 1,021 & 499 & 275 & 933 & 638 & 217 \\
\hline$I_{\max }(\mathrm{pA})$ & $61.1 \pm 2.9$ & $61.2 \pm 2.4$ & $50.4 \pm 1.9$ & $79.6 \pm 2.0$ & $73.4 \pm 3.1$ & $52.2 \pm 2.3$ \\
\hline Half width (ms) & $28.2 \pm 4.2$ & $30.1 \pm 4.1$ & $46.8 \pm 2.9$ & $21.6 \pm 2.6$ & $22.5 \pm 3.3$ & $47.8 \pm 3.1$ \\
\hline$Q(\mathrm{fC})$ & $1780 \pm 170$ & $1770 \pm 80$ & $1750 \pm 120$ & $1790 \pm 90$ & $1720 \pm 120$ & $1790 \pm 50$ \\
\hline Slope $(\mathrm{pA} / \mathrm{ms})$ & $6.1 \pm 0.9$ & $5.8 \pm 0.9$ & $2.9 \pm 0.8$ & $10.9 \pm 0.7$ & $11.2 \pm 1.5$ & $3.1 \pm 0.7$ \\
\hline Rise time (ms) & $10.2 \pm 1.8$ & $11.5 \pm 1.5$ & $18.1 \pm 1.2$ & $7.1 \pm 1.1$ & $7.1 \pm 1.1$ & $19.1 \pm 2.1$ \\
\hline Decay time (ms) & $58.9 \pm 5.9$ & $60.9 \pm 3.5$ & $65.8 \pm 2.2$ & $35.7 \pm 2.0$ & $38.8 \pm 3.2$ & $64.1 \pm 4.0$ \\
\hline Spike with foot (\%) & 29 & 26 & 32 & 17 & 16 & 27 \\
\hline Number of feet analyzed & 304 & 129 & 89 & 159 & 102 & 59 \\
\hline Number of feet per cell & $5.4 \pm 0.9$ & $5.1 \pm 0.9$ & $2.7 \pm 0.8$ & $4.0 \pm 0.4$ & $4.0 \pm 0.8$ & $2.4 \pm 0.7$ \\
\hline I foot $(\mathrm{pA})$ & $4.4 \pm 0.6$ & $4.4 \pm 0.8$ & $4.5 \pm 0.7$ & $5.4 \pm 0.7$ & $4.9 \pm 0.7$ & $4.1 \pm 0.5$ \\
\hline$Q$ foot $(\mathrm{fC})$ & $20.8 \pm 2.1$ & $20.8 \pm 2.3$ & $31.3 \pm 3.4$ & $15.3 \pm 4.4$ & $14.3 \pm 3.4$ & $30.6 \pm 1.9$ \\
\hline$t$ foot $(\mathrm{ms})$ & $14.7 \pm 2.1$ & $15.7 \pm 1.9$ & $24.3 \pm 2.1$ & $9.3 \pm 2.5$ & $8.3 \pm 2.1$ & $23.5 \pm 0.9$ \\
\hline
\end{tabular}


shows a 3D representation of the cortical actin meshwork associated to the docked granules of a nicotine-stimulated chromaffin cell treated with WA. Supplement S1 contains Excel macro Bivariate_Kv3.0, which was written in Visual Basic, provided by J.F. Hancock, and used to determine colocalization of the two proteins by analyzing the extent to which the two populations of gold particles were clustered with respect to each other. Online supplemental material is available at http:// www.jcb.org/cgi/content/full/jcb.201412030/DC1.

\section{Acknowledgements}

We thank Drs. N. Grant and S. Gasman for helpful comments and critical reading of the manuscript and $\mathrm{T}$. Thahouly for technical assistance.

This work was supported by Agence Nationale de la Recherche grant ANR-09-BLAN-0326-01 (to N. Vitale).

The authors declare no competing financial interests.

Author contributions: M-F. Bader and S. Chasserot-Golaz designed the study, project, and experiments. M. Gabel performed immunolabeling and transfection experiments. F. Delavoie performed and analyzed electron tomography. V. Demais, C. Royer, and Y. Bailly performed and analyzed electron microscopy. N. Vitale performed, analyzed, and discussed amperometry experiments. M.-F. Bader and S. Chasserot-Golaz drafted the manuscript.

Submitted: 5 December 2014

Accepted: 23 July 2015

\section{References}

Ammar, M.R., N. Kassas, S. Chasserot-Golaz, M.F. Bader, and N. Vitale. 2013. Lipids in regulated exocytosis: What are they doing? Front. Endocrinol. (Lausanne). 4:125.

Aoyagi, K., T. Sugaya, M. Umeda, S. Yamamoto, S. Terakawa, and M. Takahashi. 2005. The activation of exocytotic sites by the formation of phosphatidylinositol 4,5-bisphosphate microdomains at syntaxin clusters. J. Biol. Chem. 280:17346-17352. http://dx.doi.org/10.1074/jbc.M413307200

Astro, V., and I. de Curtis. 2015. Plasma membrane-associated platforms: dynamic scaffolds that organize membrane-associated events. Sci. Signal. 8:re1. http://dx.doi.org/10.1126/scisignal.aaa3312

Bader, M.F., J.M. Trifaró, O.K. Langley, D. Thiersé, and D. Aunis. 1986. Secretory cell actin-binding proteins: identification of a gelsolin-like protein in chromaffin cells. J. Cell Biol. 102:636-646. http://dx.doi. org/10.1083/jcb.102.2.636

Berberian, K., A.J. Torres, Q. Fang, K. Kisler, and M. Lindau. 2009. F-actin and myosin II accelerate catecholamine release from chromaffin granules. J. Neurosci. 29:863-870. http://dx.doi.org/10.1523/ JNEUROSCI.2818-08.2009

Bharadwaj, A., M. Bydoun, R. Holloway, and D. Waisman. 2013. Annexin A2 heterotetramer: structure and function. Int. J. Mol. Sci. 14:6259-6305. http://dx.doi.org/10.3390/ijms14036259

Chasserot-Golaz, S., N. Vitale, I. Sagot, B. Delouche, S. Dirrig, L.A. Pradel, J.P. Henry, D. Aunis, and M.F. Bader. 1996. Annexin II in exocytosis: catecholamine secretion requires the translocation of p36 to the subplasmalemmal region in chromaffin cells. J. Cell Biol. 133:1217-1236. http:// dx.doi.org/10.1083/jcb.133.6.1217

Chasserot-Golaz, S., N. Vitale, E. Umbrecht-Jenck, D. Knight, V. Gerke, and M.F. Bader. 2005. Annexin 2 promotes the formation of lipid microdomains required for calcium-regulated exocytosis of dense-core vesicles. Mol. Biol. Cell. 16:1108-1119. http://dx.doi.org/10.1091/mbc. E04-07-0627

Chasserot-Golaz, S., J.R. Coorssen, F.A. Meunier, and N. Vitale. 2010. Lipid dynamics in exocytosis. Cell. Mol. Neurobiol. 30:1335-1342. http://dx.doi. org/10.1007/s10571-010-9577-x

Chiang, H.C., W. Shin, W.D. Zhao, E. Hamid, J. Sheng, M. Baydyuk, P.J. Wen, A. Jin, F. Momboisse, and L.G. Wu. 2014. Post-fusion structural changes and their roles in exocytosis and endocytosis of dense-core vesicles. Nat. Commun. 5:3356. http://dx.doi.org/10.1038/ncomms4356

Cookson, E.A., I.L. Conte, J. Dempster, M.J. Hannah, and T. Carter. 2013. Characterisation of Weibel-Palade body fusion by amperometry in endothelial cells reveals fusion pore dynamics and the effect of cholesterol on exocytosis. J. Cell Sci. 126:5490-5499. http://dx.doi.org/10.1242/ jcs. 138438

Desnos, C., J.S. Schonn, S. Huet, V.S. Tran, A. El-Amraoui, G. Raposo, I. Fanget, C. Chapuis, G. Ménasché, G. de Saint Basile, et al. 2003. Rab27A and its effector MyRIP link secretory granules to F-actin and control their motion towards release sites. J. Cell Biol. 163:559-570. http://dx.doi. org/10.1083/jcb.200302157

Dinic, J., P. Ashrafzadeh, and I. Parmryd. 2013. Actin filaments attachment at the plasma membrane in live cells cause the formation of ordered lipid domains. Biochim. Biophys. Acta. 1828:1102-1111. http://dx.doi. org/10.1016/j.bbamem.2012.12.004

Donato, R. 2001. S100: a multigenic family of calcium-modulated proteins of the EF-hand type with intracellular and extracellular functional roles. Int. J. Biochem. Cell Biol. 33:637-668. http://dx.doi.org/10.1016/ S1357-2725(01)00046-2

Drücker, P., M. Pejic, H.J. Galla, and V. Gerke. 2013. Lipid segregation and membrane budding induced by the peripheral membrane binding protein annexin A2. J. Biol. Chem. 288:24764-24776. http://dx.doi.org/10.1074/ jbc.M113.474023

Falsey, R.R., M.T. Marron, G.M. Gunaherath, N. Shirahatti, D. Mahadevan, A.A. Gunatilaka, and L. Whitesell. 2006. Actin microfilament aggregation induced by withaferin A is mediated by annexin II. Nat. Chem. Biol. 2:33-38. http://dx.doi.org/10.1038/nchembio755

Gasman, S., S. Chasserot-Golaz, M. Malacombe, M. Way, and M.F. Bader. 2004. Regulated exocytosis in neuroendocrine cells: a role for subplasmalemmal Cdc42/N-WASP-induced actin filaments. Mol. Biol. Cell. 15:520531. http://dx.doi.org/10.1091/mbc.E03-06-0402

Gerke, V., C.E. Creutz, and S.E. Moss. 2005. Annexins: linking $\mathrm{Ca}^{2+}$ signalling to membrane dynamics. Nat. Rev. Mol. Cell Biol. 6:449-461. http://dx.doi. org/10.1038/nrm1661

Gokhale, N.A., A. Abraham, M.A. Digman, E. Gratton, and W. Cho. 2005. Phosphoinositide specificity of and mechanism of lipid domain formation by annexin A2-p11 heterotetramer. J. Biol. Chem. 280:42831-42840. http://dx.doi.org/10.1074/jbc.M508129200

Gutiérrez, L.M. 2012. New insights into the role of the cortical cytoskeleton in exocytosis from neuroendocrine cells. Int. Rev. Cell. Mol. Biol. 295:109137. http://dx.doi.org/10.1016/B978-0-12-394306-4.00009-5

Hancock, J.F., and I.A. Prior. 2005. Electron microscopic imaging of Ras signaling domains. Methods. 37:165-172. http://dx.doi.org/10.1016/j. ymeth.2005.05.018

Harder, T., P. Scheiffele, P. Verkade, and K. Simons. 1998. Lipid domain structure of the plasma membrane revealed by patching of membrane components. J. Cell Biol. 141:929-942. http://dx.doi.org/10.1083/jcb.141.4.929

Hayes, M.J., D. Shao, M. Bailly, and S.E. Moss. 2006. Regulation of actin dynamics by annexin 2. EMBO J. 25:1816-1826. http://dx.doi.org/10.1038/ sj.emboj.7601078

Hitchcock, J.K., A.A. Katz, and G. Schäfer. 2014. Dynamic reciprocity: the role of annexin A2 in tissue integrity. J. Cell Commun. Signal. 8:125-133. http://dx.doi.org/10.1007/s12079-014-0231-0

Ikebuchi, N.W., and D.M. Waisman. 1990. Calcium-dependent regulation of actin filament bundling by lipocortin-85. J. Biol. Chem. 265:3392-3400.

Jahn, R., and D. Fasshauer. 2012. Molecular machines governing exocytosis of synaptic vesicles. Nature. 490:201-207. http://dx.doi.org/10.1038/ nature 11320

Janes, P.W., S.C. Ley, and A.I. Magee. 1999. Aggregation of lipid rafts accompanies signaling via the T cell antigen receptor. J. Cell Biol. 147:447-461. http://dx.doi.org/10.1083/jcb.147.2.447

Jones, P.G., G.J. Moore, and D.M. Waisman. 1992. A nonapeptide to the putative F-actin binding site of annexin-II tetramer inhibits its calcium-dependent activation of actin filament bundling. J. Biol. Chem. 267:13993-13997.

Kremer, J.R., D.N. Mastronarde, and J.R. McIntosh. 1996. Computer visualization of three-dimensional image data using IMOD. J. Struct. Biol. 116:71-76. http://dx.doi.org/10.1006/jsbi.1996.0013

Lang, T. 2007. SNARE proteins and 'membrane rafts'. J. Physiol. 585:693-698. http://dx.doi.org/10.1113/jphysiol.2007.134346

Lewit-Bentley, A., S. Réty, J. Sopkova-de Oliveira Santos, and V. Gerke. 2000. S100-annexin complexes: some insights from structural studies. Cell Biol. Int. 24:799-802. http://dx.doi.org/10.1006/cbir.2000.0629

Malacombe, M., M.F. Bader, and S. Gasman. 2006. Exocytosis in neuroendocrine cells: new tasks for actin. Biochim. Biophys. Acta. 1763:1175-1183. http://dx.doi.org/10.1016/j.bbamcr.2006.09.004 
Miklavc, P., E. Hecht, N. Hobi, O.H. Wittekindt, P. Dietl, C. Kranz, and M. Frick. 2012. Actin coating and compression of fused secretory vesicles are essential for surfactant secretion - a role for Rho, formins and myosin II. J. Cell Sci. 125:2765-2774. http://dx.doi.org/10.1242/jcs.105262

Monck, J.R., A.F. Oberhauser, G. Alvarez de Toledo, and J.M. Fernandez. 1991. Is swelling of the secretory granule matrix the force that dilates the exocytotic fusion pore? Biophys. J. 59:39-47. http://dx.doi.org/10.1016/ S0006-3495(91)82196-8

Nakata, T., K. Sobue, and N. Hirokawa. 1990. Conformational change and localization of calpactin I complex involved in exocytosis as revealed by quick-freeze, deep-etch electron microscopy and immunocytochemistry. J. Cell Biol. 110:13-25. http://dx.doi.org/10.1083/jcb.110.1.13

Ozorowski, G., C.M. Ryan, J.P. Whitelegge, and H. Luecke. 2012. Withaferin A binds covalently to the N-terminal domain of annexin A2. Biol. Chem. 393:1151-1163. http://dx.doi.org/10.1515/hsz-2012-0184

Papadopulos, A., S. Martin, V.M. Tomatis, R.S. Gormal, and F.A. Meunier. 2013a. Secretagogue stimulation of neurosecretory cells elicits filopodial extensions uncovering new functional release sites. J. Neurosci. 33:19143-19153. http://dx.doi.org/10.1523/JNEUROSCI.2634-13.2013

Papadopulos, A., V.M. Tomatis, R. Kasula, and F.A. Meunier. 2013b. The cortical acto-Myosin network: from diffusion barrier to functional gateway in the transport of neurosecretory vesicles to the plasma membrane. Front. Endocrinol. (Lausanne). 4:153.

Pettersen, E.F., T.D. Goddard, C.C. Huang, G.S. Couch, D.M. Greenblatt, E.C. Meng, and T.E. Ferrin. 2004. UCSF Chimera-a visualization system for exploratory research and analysis. J. Comput. Chem. 25:16051612. http://dx.doi.org/10.1002/jcc.20084

Poëa-Guyon, S., M.R. Ammar, M. Erard, M. Amar, A.W. Moreau, P. Fossier, V. Gleize, N. Vitale, and N. Morel. 2013. The V-ATPase membrane domain is a sensor of granular $\mathrm{pH}$ that controls the exocytotic machinery. J. Cell Biol. 203:283-298. http://dx.doi.org/10.1083/jcb.201303104

Rescher, U., N. Zobiack, and V. Gerke. 2000. Intact $\mathrm{Ca}^{2+}$-binding sites are required for targeting of annexin 1 to endosomal membranes in living HeLa cells. J. Cell Sci. 113:3931-3938.

Rescher, U., C. Ludwig, V. Konietzko, A. Kharitonenkov, and V. Gerke. 2008. Tyrosine phosphorylation of annexin A2 regulates Rho-mediated actin rearrangement and cell adhesion. J. Cell Sci. 121:2177-2185. http://dx.doi. org/10.1242/jcs.028415

Rotblat, B., I.A. Prior, C. Muncke, R.G. Parton, Y. Kloog, Y.I. Henis, and J.F. Hancock. 2004. Three separable domains regulate GTP-dependent association of H-ras with the plasma membrane. Mol. Cell. Biol. 24:6799-6810. http://dx.doi.org/10.1128/MCB.24.15.6799-6810.2004

Saka, S.K., A. Honigmann, C. Eggeling, S.W. Hell, T. Lang, and S.O. Rizzoli. 2014. Multi-protein assemblies underlie the mesoscale organization of the plasma membrane. Nat. Commun. 5:4509. http://dx.doi.org/10.1038/ ncomms5509

Sankaranarayanan, S., P.P. Atluri, and T.A. Ryan. 2003. Actin has a molecular scaffolding, not propulsive, role in presynaptic function. Nat. Neurosci. 6:127-135. http://dx.doi.org/10.1038/nn1002
Sebastião, A.M., M. Colino-Oliveira, N. Assaife-Lopes, R.B. Dias, and J.A. Ribeiro. 2013. Lipid rafts, synaptic transmission and plasticity: impact in age-related neurodegenerative diseases. Neuropharmacology. 64:97-107. http://dx.doi.org/10.1016/j.neuropharm.2012.06.053

Segura, F., M.A.Brioso, J.F.Gómez, J.D.Machado, and R.Borges. 2000 Automatic analysis for amperometrical recordings of exocytosis. J. Neurosci. Methods. 103:151-156. http://dx.doi.org/10.1016/S01650270(00)00309-5

Sontag, J.M., D. Aunis, and M.F. Bader. 1988. Peripheral actin filaments control calcium-mediated catecholamine release from streptolysin-O-permeabilized chromaffin cells. Eur. J. Cell Biol. 46:316-326.

Tomatis, V.M., A. Papadopulos, N.T. Malintan, S. Martin, T. Wallis, R.S. Gormal, J. Kendrick-Jones, F. Buss, and F.A. Meunier. 2013. Myosin VI small insert isoform maintains exocytosis by tethering secretory granules to the cortical actin. J. Cell Biol. 200:301-320. http://dx.doi.org/10.1083/ jcb.201204092

Toonen, R.F., O. Kochubey, H. de Wit, A. Gulyas-Kovacs, B. Konijnenburg, J.B. Sørensen, J. Klingauf, and M. Verhage. 2006. Dissecting docking and tethering of secretory vesicles at the target membrane. EMBO J. 25:3725-3737. http://dx.doi.org/10.1038/sj.emboj.7601256

Torregrosa-Hetland, C.J., J. Villanueva, V. Garcia-Martínez, G. ExpósitoRomero, M.M. Francés, and L.M. Gutiérrez. 2013. Cortical F-actin affects the localization and dynamics of SNAP-25 membrane clusters in chromaffin cells. Int. J. Biochem. Cell Biol. 45:583-592. http://dx.doi. org/10.1016/j.biocel.2012.11.021

Umbrecht-Jenck, E., V. Demais, V. Calco, Y. Bailly, M.F. Bader, and S. ChasserotGolaz. 2010. S100A10-mediated translocation of annexin-A2 to SNARE proteins in adrenergic chromaffin cells undergoing exocytosis. Traffic. 11:958-971. http://dx.doi.org/10.1111/j.1600-0854.2010.01065.x

Vitale, N., J. Moss, and M. Vaughan. 1996. ARD1, a 64-kDa bifunctional protein containing an 18-kDa GTP-binding ADP-ribosylation factor domain and a 46-kDa GTPase-activating domain. Proc. Natl. Acad. Sci. USA 93:1941-1944. http://dx.doi.org/10.1073/pnas.93.5.1941

Wilson, B.S., S.L. Steinberg, K. Liederman, J.R. Pfeiffer, Z. Surviladze, J. Zhang, L.E. Samelson, L.H. Yang, P.G. Kotula, and J.M. Oliver. 2004. Markers for detergent-resistant lipid rafts occupy distinct and dynamic domains in native membranes. Mol. Biol. Cell. 15:2580-2592. http:// dx.doi.org/10.1091/mbc.E03-08-0574

Zhang, J., K. Leiderman, J.R. Pfeiffer, B.S. Wilson, J.M. Oliver, and S.L. Steinberg. 2006a. Characterizing the topography of membrane receptors and signaling molecules from spatial patterns obtained using nanometer-scale electron-dense probes and electron microscopy. Micron. 37:14-34. http://dx.doi.org/10.1016/j.micron.2005.03.014

Zhang, Z., A.K. Ottens, S.F. Larner, F.H. Kobeissy, M.L. Williams, R.L. Hayes, and K.K. Wang. 2006b. Direct Rho-associated kinase inhibition [correction of inhibiton] induces cofilin dephosphorylation and neurite outgrowth in PC-12 cells. Cell. Mol. Biol. Lett. 11:12-29. http://dx.doi. org/10.2478/s11658-006-0002-x

Zobiack, N., V. Gerke, and U. Rescher. 2001. Complex formation and submembranous localization of annexin 2 and S100A10 in live HepG2 cells. FEBS Lett. 500:137-140. http://dx.doi.org/10.1016/S0014-5793(01)02604-7 